\title{
EL POSITIVISMO EN EL DERECHO PENAL CHILENO. ANÁLISIS SINCRÓNICO Y DIACRÓNICO DE UNA DOCTRINA DE PRINCIPIOS DEL SIGLO XX QUE SE MANTIENE VIGENTE*
}

\author{
Jean Pierre Matus Acuña**
}

\begin{abstract}
RESUMEN
El artículo describe, contra la opinión mayoritaria, cómo el positivismo penal se desarrolló en Chile desde principios del siglo XX, a partir de la influencia de Valentín Letelier y Raimundo del Río en la enseñanza universitaria. Da cuenta del impacto de las ideas positivistas en otros autores de la época, en los proyectos de Código penal de Erazo-Fontecilla (1929) y Silva-Labatut (1938), y las leyes sobre Estados Antisociales $\left(N^{\circ} 11.265\right)$ y Remisión Condicional de la Pena ( $\left.N^{o} 7.821\right)$; sustentando la hipótesis, contraria a la opinión dominante, de que las tesis positivistas permanecen vigentes en nuestro ordenamiento punitivo y especialmente en la práctica procesal, al punto de que nuestro actual sistema de penas, incluyendo las salidas alternativas ("suspensión condicional del procedimiento"), las "sanciones" de la Ley de Responsabilidad Adolescente $N^{o} 20.084$ y las medidas de la Ley $N^{o} 18.216$ ("remisión condicional" y "libertad vigilada"), puede ser descrito en clave "positivista", al determinarse la duración y clase las medidas efectivamente a imponer principalmente por criterios relativos a la "peligrosidad" del imputado.
\end{abstract}

\section{POSITIVISMO PENAL - PELIGROSIDAD - HISTORIA DEL DERECHO PENAL CHILENO}

\section{Positivism in chilean criminal law. A synchronic and diachronic analysis of an early $20^{\text {th }}$ century doctrine still in use}

\section{ABSTRACT}

Against the predominant opinion, this article describes how Criminal Positivism developed in Chile since the early $20^{\text {th }}$ Century, starting from the influences of Valentin Letelier and Raimundo del Rio in their university teachings. This work acknowledges the impact positivist ideas had on other contemporary authors, on the Erazo-Fontecilla (1929) and Silva-Labatut (1938) Criminal Code projects, on the Antisocial States Act (11.265) and on the Conditional Remission of Punishment Act (7.821); contrary to the dominant view, the author sustains the hypothesis that positivist theses remain effective in our criminal law system, especially in criminal procedural practices, to the extent that our actual punitive system, including alternative sentencing (conditional suspension of procedure), the "sanctions" contemplated in the Teenage Responsibility Law Number 20.084 and the measures of Law Number 18.216 (conditional remission and parole), can be described as positivist, because the length and type of effectively imposed measures are mostly determined on the basis of criteria regarding the accused's dangerousness.

\section{CRIMINAL POSITIVISM - DANGEROUSNESS - HISTORY OF CRIMINAL CHILEAN LAW}

* Artículo elaborado como resultado del Proyecto FONDECYT N 1051022, "Evolución de la doctrina penal chilena, desde el código de 1874 hasta nuestros días. Análisis Diacrónico y sincrónico".

** Abogado, Doctor en Derecho, Profesor de Derecho Penal, Director Centro de Estudios de Derecho Penal, Universidad de Talca, Campus Santiago, Chile, director@dpenal.cl, artículo recibido el 7 de diciembre de 2006 y aceptado para su publicación por el Comité Editorial el 4 de mayo de 2007. 


\section{INTRODUCCIÓN}

$\mathrm{E}$ s común en los textos de estudio al uso hoy día señalar que el positivismo llegó a Chile "tardíamente" - "a comienzos de la década del cuarenta" del siglo XX-; ${ }^{1}$ que "su influencia se advierte particularmente en la obra de Raimundo del Río"; 2 que ya a principios de los años sesenta del siglo XX quedaban sólo "algunos positivistas, pero no de aquellos que querían desplazar el Derecho a un papel secundario en las ciencias del delito"; 3 y que, "afortunadamente", su "ideología" se mantuvo sólo "en los límites de la retórica académica"; ${ }^{4}$ dejando únicamente como recuerdo "la aparición de los primeros trabajos de investigación criminológica” dados a la luz en la prácticamente extinta Revista de Ciencias Penales, ${ }^{5}$ una ley cuya aplicación práctica nunca se llevó a efecto completamente: la ya derogada $\mathrm{N}^{\circ} 11.625$, de 4 de octubre de 1954 , sobre Estados Antisociales, ${ }^{6}$ y la introducción del sistema de "remisión condicional" de la pena, "como un recurso para combatir las consecuencias indeseables de las penas cortas privativas de libertad", por la Ley $\mathrm{N}^{\circ} 7.821$, de 20 de agosto de $1944,{ }^{7}$ recogido actualmente en la Ley $\mathrm{N}^{\circ} 18.216$, de 14 de mayo de 1983.

En este lugar pondremos a prueba esas afirmaciones, investigando si más allá de nuestras solemnes declaraciones acerca del "estancamiento que provocó en el avance del derecho penal", ${ }^{8}$ consciente o inconscientemente el positivismo sigue influyendo entre nosotros, al punto de hacerlo incluso en el Anteproyecto de Código penal de 2005. Para ello haremos primero una revisión somera del positivismo en Chile; luego, veremos en qué medida sus tesis perviven en la doctrina penal nacional -sin considerar el avance en el conjunto de disciplinas que se engloban bajo lo que llamamos propiamente

\footnotetext{
${ }^{1}$ Cury U., Enrique. Derecho penal. Parte General. $7^{\text {a }}$ ed. Santiago: Ediciones Universidad Católica de Chile, 2005.812 p., p. 161.

${ }^{2}$ Etcheberry O., Alfredo. Derecho penal, t. I. $3^{\text {a }}$ ed. Santiago: Editorial Jurídica de Chile, 1998. 361 p., p. 59.

${ }^{3}$ Novoa M., Eduardo. Curso de Derecho penal, t. I. Santiago: Editorial Jurídica de Chile, 1960. 618 p., p. 90.

${ }^{4}$ Politoff, Sergio; Matus, Jean Pierre; Ramírez, M ${ }^{\mathrm{a}}$ Cecilia. Lecciones de Derecho penal. Parte general. $2^{\mathrm{a}}$ ed. Santiago: Editorial Jurídica de Chile, 2004.613 p., p. 33.

${ }^{5}$ Politoff, Sergio. Derecho penal. $2^{\text {a }}$ ed. Santiago: Editorial Jurídica Cono Sur, 2001. 497 p., p. 50. La Revista de Ciencias Penales nació el año 1935 al alero de los esfuerzos de positivistas, transformados en criminólogos, como Israel Drapkin, Director del Instituto Nacional de Clasificación de Criminología de la Dirección General de Prisiones, y Manuel Jara Cristi, Director de dicho Servicio ("Revista de Ciencias Penales". Revista de Ciencias Penales, t. I, 1935, p. 1). Ellos también impulsaron la creación del Instituto de Ciencias Penales en 1937, cuyo primer presidente fue Raimundo del Río ("Instituto de Ciencias Penales", "Estatutos” y “Acta de Fundación”. Revista de Ciencias Penales, t. III, 1937, p. 281-290). El Instituto se hizo cargo de la edición de la Revista a partir del año 1938, nombrándose como director a Abraham Drapkin, como aparece en la portada del primer número del t. IV, correspondiente a dicho año.

${ }^{6}$ El Proyecto original fue aprobado por el Instituto de Ciencias Penales en las "Asambleas de estudio" celebradas los días 7, 14, 21 y 28 de agosto y 4, 11 y 24 de septiembre de 1941 ("Proyecto de Ley Sobre Estados Antisociales y Medidas de Seguridad”. Revista de Ciencias Penales, t. IV, 1941, p. 60-68).

${ }^{7}$ Cury U., Derecho penal, p. 161.

${ }^{8}$ Cousiño, Luis. Derecho penal chileno, t. I. Santiago: Editorial Jurídica de Chile, 1975.960 p., p. 68.
} 
“criminología”, donde la criminología positiva ha logrado un lugar importante, si no preponderante, en estos últimos años-; ${ }^{9}$ y finalmente, averiguaremos si algo de ellas pervive en el mencionado Anteproyecto.

\section{i. El positivismo en Chile: De Letelier a Del Río}

\subsection{Los orígenes: Letelier y su influencia posterior}

Contra la opinión dominante recién reproducida, el positivismo no fue introducido en Chile tan tardíamente como se dice (década de 1940), sino ya a finales del siglo XIX, a través de las enseñanzas de don Valentín Letelier, profesor de ¡Derecho Administrativo! de la Universidad de Chile desde fines del siglo XIX, y su Rector a la vuelta del siglo. ${ }^{10}$ Su influencia en todas las áreas del Derecho se debió tanto al hecho de que en sus clases "dio más importancia a los fundamentos, a la teoría, a los principios generales de la rama del Derecho que enseñaba, que a los preceptos positivos”, como por su especial preocupación por acercarse a sus estudiantes, con lo que "rompió esa muralla de convencionalismo que hacía del profesor un ser inaccesible, sin otro contacto con sus discípulos que el estricto de la hora de clase y el angustioso de los exámenes", conviviendo con ellos y "sirviéndoles de guía y consejero", llegando a considerársele "un pedagogo de fuste, y un maestro en todo el sentido de la palabra". ${ }^{11}$

\footnotetext{
${ }^{9}$ Según se explica en Politoff / Matus / Ramírez, Lecciones PG, p. 89, la criminología en Chile ha estado marcada por los esfuerzos individuales de científicos motivados, como Israel Drapkin y, más tarde, Marco A. González Berendique (Criminología. 2 vols. Santiago: Editorial Jurídica de Chile, 1998), y los institutos de Gendarmería de Chile (que edita la Revista de Estudios Penales y Criminológicos), la Policía de Investigaciones y, actualmente, la División de Seguridad Ciudadana del Ministerio del Interior (a título ilustrativo, véase el trabajo de Araya Moya, Jorge; Sierra Cisternas, David. Influencia de factores de riesgo social en el origen de conductas delictuales. Índice de vulnerabilidad social, delincuencia comunal. Santiago: División de Seguridad Ciudadana del Ministerio del Interior, 2002. Se puede consultar también la serie completa de publicaciones de esta División en http://www.seguridadciudadana.gob.cl/PNSCdoc.html [visitado el 28.11.2006], junto con estadísticas y otras informaciones relevantes). También universidades e instituciones privadas, como la Fundación Paz Ciudadana, realizan estudios criminológicos modernos, como puede verse en http://www. pazciudadana.cl [visitado el 28.11.2006], y nuestros propios resultados publicados en Política Criminal (http://www.politicacriminal.cl), como el texto de Cea, Macarena; Ruiz, Paulina; y Matus, Jean Pierre. "Determinantes de la criminalidad. Revisión bibliográfica". Polít. crim. No 2, 2006, D4. Pero también se realiza hoy en día criminología etiológica y descriptiva: a título ilustrativo, pueden consultarse las siguientes obras: Antony García, Carmen. Las mujeres confinadas. Estudio criminológico sobre el rol genérico en la ejecución de la pena en Chile y América Latina. Santiago, 2000; y Jiménez, M ${ }^{a}$ Angélica. "Núcleos problemáticos de las medidas alternativas a la privación de libertad (Referencia a países de América Latina)". Cuadernos de Análisis Jurídico $\mathrm{N}^{\circ}$ 30, 1994, pp. 41-52.

${ }^{10} \mathrm{Su}$ biografía y copiosa bibliografía en los temas políticos y administrativos puede verse en De Ramón, Armando y otros. Biografías de Chilenos. vol. III. Santiago: Ediciones de la P. U. Católica de Chile, 2003, 298 p., p. 46, N² 2083.

${ }^{11}$ Baeza, Mario. Esquema y notas para una historia de la Facultad de Ciencias Jurídicas y Sociales de la Universidad de Chile. Santiago: Memoria de Prueba (Universidad de Chile), 1944. 237 p., 182 y siguiente.
} 
Según Letelier, el positivismo penal nace como reacción al hecho de que la aplicación de los postulados de la escuela clásica durante todo el siglo XIX los había llevado al descrédito, pues

“... después de haber mejorado sin duda los procedimientos criminales i los rejímenes carcelarios, no hiceron más que poner de manifiesto cuánta era su impotencia para preservar a los pueblos de la plaga de la criminalidad [...] por efecto de dos causas principales: en primer lugar, su ineptitud para lograr sus fines, como lo prueba el hecho de que el número de reincidentes sea mayor cuando más escrupulosamente se las aplica; i en segundo, su inequidad, pues cuando imputa toda la culpa al delincuente, exime de toda responsabilidad a la sociedad que lo ha formado, educado i guiado i que con apatía ante la miseria, con su tolerancia de la corrupción, con la ostentación de su lujo i con sus serviles adulaciones a los vencedores de la vida, lo ha tentado, lo ha estimulado i lo ha empujado". ${ }^{12}$

Ya al escribir esas palabras, Letelier había comprendido que la Escuela Antropológica de Lombroso ${ }^{13}$-difundida entre los médicos nacionales por el Dr. Luis Gambara, "Delegado general de la Escuela Positiva Penal en las Repúblicas Hispano-Americanas", quien dictó un curso completo de "Derecho Penal Positivo" en la Sociedad Médica de Santiago, el que fue impreso Santiago en $1906^{14}$ - sólo abarcaba un capítulo de la “criminología positiva” y "no podía abrazar todo el derecho penal”, por lo que quedaba pendiente la labor de "reconstruir sobre bases positivas la ciencia del derecho penal", lo que sólo podría hacerse estudiando el derecho "a la manera de un fenómeno social, esto es, de un fenómeno que nace, se desarrolla i se modifica a medida de las necesidades de cada pueblo en cada momento de su vida", ${ }^{15}$ a la manera de Garófalo y Ferri. ${ }^{16}$ Luego,

${ }^{12}$ Letelier, Valentín. Jénesis del Derecho. Santiago y Buenos Aires: Hume \& Walker y Cabaut \& Cía., 1919. 727 p., p. 414.

${ }^{13}$ Cuya obra cúlmine es sin duda el Atlas (Lombroso, César. L'Homme Criminel. Atlas. 12 ed. Turín: Bocca Frères, 1888), que contiene 90 planchas de estudios de criminales, para demostrar a través de dibujos y fotografías la existencia del "hombre delincuente" y "responder, así, a ciertos antropólogos más o menos serios que niegan la existencia de tipos de cráneo compartido entre los criminales".

${ }^{14}$ Gambara, Luis. Curso de Derecho penal positivo. Santiago: Hnos. Ponce, 1906. 184 p.

${ }^{15}$ Letelier, Jénesis, pp. 415-417. Aunque la obra está fechada en 1919, hay que tener presente que, según las propias palabras del autor, las ideas en ella recogidas se venían "elaborando años atrás” (p. xviii).

${ }^{16}$ Letelier, Jénesis, p. 416, nota $(t)$ cita expresamente como apoyo de su doctrina la sustentada en la versión francesa del texto de Garófalo, Raffaele. La criminologie. Paris: Félix Alcan, 1905 (Hay versión en castellano: Garófalo, Raffaele. La criminología: estudio sobre el delito y sobre la teoría de la represión. Trad. P. Dorado Montero. Madrid: La España Moderna, 1885); y la de Ferri, Enrico. La sociologie criminelle. Paris: Félix Alcan, 1914 (un resumen maduro de las tesis de Ferri puede verse en la versión castellana de su texto de 1927: Ferri, Enrique. Principios de Derecho Criminal. Delincuente y delito en la ciencia, la legislación y la jurisprudencia. Trad. J. Rodríguez Muñoz. Madrid: Reus, 1933), y aunque señala que "todos los penalistas de la escuela positiva adhirieron a Ferri", su propia adhesión "no es absoluta", pues no acepta "la negación del libre albedrío ... un hecho que la filosofía positiva tiene que reconocer en tanto cuanto reconoce que son modificables las leyes naturales". 
sin limitarse a reproducir el pensamiento de estos autores y con erudición encomiable, ${ }^{17}$ repasa los datos disponibles en ese momento sobre la fenomenología del derecho penal en las distintas sociedades y períodos históricos, para concluir que "el delito deber ser un fenómeno de carácter mui relativo" si "cambia de un lugar a otro i de uno a otro tiempo", sujeto sólo a "una lei", "la de amoldarse al estado social". ${ }^{18}$

"El delito, por consiguiente, no nace caprichosamente. Si esceptuamos los casos de torpezas del legislador, torpezas que comete cuando pretende castigar actos, como la lectura de libros prohibidos, que el sentimiento público no condena, nace en su lugar i en su tiempo a medida que lo requieren las necesidades del órden social. Obra espontánea de la conciencia de los pueblos, los legisladores pueden declararlo, castigarlo o dejarlo impune, pero en el fondo no tienen potestad para crearlo". ${ }^{19}$

Hasta aquí llega la investigación de Letelier. Aunque explícitamente rechaza entrar a la discusión acerca de las finalidades de la pena, y sólo menciona las tesis del propio Ferri y de Dorado Montero, ${ }^{20}$ su investigación acerca de la génesis positiva (sociológica) del delito sólo parece apuntar a abrir el camino de investigaciones de similar carácter, que pudieran contribuir, efectivamente (al contrario de las doctrinas dominantes en la época), a "preservar a los pueblos de la plaga de la criminalidad".

La influencia de Letelier y el positivismo fue notoria en los jóvenes estudiantes de Derecho de la época, según ya demostré en un trabajo anterior: más del $60 \%$ de las monografías escritas entre 1875 y 1920 correspondían a textos que se referían a la Escuela Positiva del derecho penal, con títulos de memorias de prueba como La Escuela Criminal Positiva (1917), ${ }^{21}$ El delito y su represión (1907), ${ }^{22}$ De las penas y los sistemas penitenciarios (1902), ${ }^{23}$ Antropología Criminal y Derecho Penal (1911), ${ }^{24}$ Los menores ante la legislación penal (1917), ${ }^{25}$ etc. $^{26}$ Posteriormente, se siguieron escribiendo memorias de grado

${ }^{17}$ Cita Letelier, junto a los ya mencionados Lombroso, Garófalo y Ferri, las ediciones francesas o españolas de las obras de Beccaria (Traité des Délits et des Peines), Montes (Precursores de la Ciencia Penal), Maxwel (Le concept Social du Crime), Francotte (La Antropología criminal), Tucídides (Guerre du Péloponése), Costa (Estudios Ibéricos), Estrabón (Géographie), Dingelstedt (Le régime patriarchal des Kirghizi), Tylor (Antropología), Sepencer (La Morale de différentes Peuples), etc.

${ }^{18}$ Letelier, Jénesis, p. 485 y siguiente.

${ }^{19}$ Letelier, Jénesis, p. 492. La conclusión, según aclara Letelier en nota al pie $(g z)$, es coincidente con la de Szerer, Mieczyslaw. Conception sociologique de la Peine. Paris, 1914, 205 p.

${ }^{20}$ Letelier, Jénesis, p. 492, nota al pie $(g z)$.

${ }^{21}$ Lira Valencia, Rigoberto. La Escuela Criminal positiva. Tesis UCH. Santiago, 1917, 16 p.

${ }^{22}$ Valenzuela González, Manuel. El delito y su represión. Tesis UCH. Santiago: Imp. Encina, 1907, 26 p.

${ }^{23}$ Correa Ovalle, Samuel. De las penas y los sistemas penitenciarios. Tesis UCH. Santiago: Cervantes, 1902,33 p.

${ }^{24}$ García Guerrero, Eduardo. Estudio sobre Antropología Criminal. Tesis UCH. Santiago, 1911, 26 p.

${ }^{25}$ Escudero O., Jacinto. Los menores ante la legislación penal. Tesis UCH. Santiago: La Tribuna Ilustrada, $1917,54 \mathrm{p}$.

${ }^{26}$ El resto de la bibliografía de la época puede consultarse en Matus Acuña, Jean Pierre. "Fernández, Fuenzalida y Vera: Comentaristas, autodidactas y olvidados. Análisis diacrónico y sincrónico de la doctrina 
influidas por el positivismo, con títulos tan sugerentes como Los Institutos y Seminarios de Criminología y Bases generales para el nuevo Código Penal (1928), ${ }^{27}$ Cuestiones de Antropología Jurídica (1924), ${ }^{28}$ y Estudio Jurídico y Médico Legal del Ebrio (1926). ${ }^{29}$

\subsection{Los criminólogos y penalistas positivistas en Chile}

Pero no sólo en los estudiantes de derecho la Escuela Positiva tuvo seguidores. Los primeros números de la Revista de Ciencias Penales dan cuenta del interés de investigadores en criminología como Israel ${ }^{30}$ y Abraham Drapkin Sh., quien fuera su Director, ${ }^{31}$

penal chilena del siglo XIX”. Ius et Praxis. Año 12, N 1, 2006, pp. 31-67, especialmente en las notas al pie 42 a 48 de las páginas 39 a 40, donde pueden verse los listados completos de las memorias de grado sobre temas relativos a la Escuela Positiva, escritas entre 1874 y 1920.

${ }^{27}$ Brzovic R., Miguel. Los Institutos y Seminarios de Criminología y Bases generales para el nuevo Código Penal. Tesis UCH. Santiago: Imp. Austral, 1928, 127 p. En la misma línea de reforma penal encontramos antes la memoria de Rojo C., Enrique. Tres instituciones penales prácticas y modernas. Tesis UCH. Santiago: la Economía, 1923, 79 p., y después, la de Vieytes P., Irlanda. El problema de la Esterilización de Anormales y Delincuentes. Tesis UCH. Santiago: Talleres “El Chileno”, 1947, 50 p.

${ }^{28}$ Gamboa Silva, Carmen. Cuestiones de Antropología Jurídica. Tesis UCH. Valparaíso: Imp. La Armada, 1924, 63 p. Un aspecto específico de esta temática es tratado después por Scheggia F., Mario. La reincidencia y su comprobación. Tesis UCH. Santiago: El Cóndor, 1929, 64 p.

${ }^{29}$ Espejo E., Humberto. Estudio Jurídico y Médico Legal del Ebrio. Problema social del alcoholismo. Tesis UCH. Santiago. El Globo, 1926, 83 p. El mismo tema aparece en la memoria de Ochagavía H., Ignacio. La legislación, ante el problema del Alcobolismo. Tesis UCH. Santiago: Cervantes, 1917, 60 p. Entre otras memorias sobre medicina legal, rama en ese momento fuertemente vinculada al positivismo, se pueden citar: Verdugo L., Alberto. Estudios de Medicina Legal. Santiago: Imp. Universitaria, 1920, 74 p.; Cuevas C., Luis. La pericia Médico-Legal. Sus imperfecciones en la práctica. Tesis UCH. Santiago: La Economía, 1921, 43 p.

${ }^{30}$ Israel Drapkin, desde el Servicio de Prisiones (hoy Gendarmería de Chile) fue autor de diversas obras de criminología, las más importantes, en orden de aparición: Criminología y Ciencia Penitenciaria. Santiago: Imp. de Prisiones, 1941, 20 p.; "La libertad condicional en Chile". Revista de Ciencias Penales, t. VIII, 1945, p. 103; “Algunas consideraciones acerca de la criminalidad entre los araucanos". Revista de Ciencias Penales, t. X, No 2-3, 1948, p. 106; y Prensa y Criminalidad. Santiago: Anales U. de Chile, 1958, 131 p. También trabajó en conjunto con médicos del servicio, como puede verse, a modo ejemplar, en Drapkin, Israel; Brücher E., Eduardo. Criminología y Ciencia penitenciaria. Santiago: Imp. Prisiones, 1941, 20 p., y en Drapkin, Israel; Agüero, Guillermo; Cubillos, Luis. "Proyecto de Ficha Criminológica del Instituto de Clasificación y Criminología de la Penitenciaría de Santiago". Revista de Ciencias Penales, t. II, 1936, p. 381-427.

31 Abraham Drapkin derivó de los estudios propiamente “jurídicos”, como su memoria Jurisprudencia de las circunstancias eximentes de responsabilidad criminal. Tesis UCH. Santiago, 1936, 113 p. (reproducida parcialmente en "Jurisprudencia de la eximente por enajenación mental". Revista de Ciencias Penales, t. II, 1936, p. 518-537; "La menor edad". Revista de Ciencias Penales, t. III, 1937, p. 53-59; "Defensa legítima" y "Uxoricidio por adulterio", ambas en Revista de Ciencias Penales, t. IV, 1938, p. 36-56 y p. 406-415), hacia la investigación criminológica de campo, como puede verse en sus "Apuntes para la formación del vocabulario del hampa chilena”. Revista de Ciencias Penales, t. IV, 1938, pp. 484-492. Sin embargo, nunca perdió el interés por la "técnica jurídica", como se aprecia en su texto autónomo Relación de causalidad y delito. Santiago: Cruz del Sur, 1943, 114 p. 
y los médicos Eduardo Brücher, ${ }^{32}$ Luis Cubillos $^{33}$ y Guillermo Agüero Correa, ${ }^{34}$ entre otros.

Entre los juristas que dieron a las prensas alguna obra de Derecho penal distintas a su memoria de grado, destacaron como difusores del positivismo especialmente Valentín Brandeau, Samuel Gajardo y Gustavo Labatut y Rafael Fontecilla, en sus primeros escritos. Brandeau escribió, aparte de su memoria de grado, una monografía sobre La represión y prevención del delito en Chile ${ }^{35}$ y las dos primeras partes de su "Introducción al Estudio del Derecho penal", cuya publicación quedó trunca, debido a "enfermedad”, según anuncia la entidad editora. ${ }^{36}$ Por su parte, Samuel Gajardo se destacó a nivel latinoamericano con su Medicina Legal, de marcado corte positivista, que tuvo una gran acogida en la enseñanza universitaria de la época, editándose una primera y modesta edición en 1931 y otra, ampliada y en dos tomos, en 1939. ${ }^{37}$

La influencia del positivismo en Gustavo Labatut Glena ${ }^{38}$ es notoria en el Proyecto de Código penal de 1938 (en colaboración con Pedro Silva Fernández): allí se propone

32 Brücher E., Eduardo. "El nuevo método de defensa social: la esterilización”. Revista de Ciencias Penales, t. I, 1935, p. 34-40; "Consideraciones sobre la reincidencia delictual en Chile" y "Anotaciones médico-legales al Proyecto de Código Penal Silva-Labatut”. Revista de Ciencias Penales, t. IV, 1938, p. 57-60 y 471-479, por mencionar sólo sus trabajos en solitario.

33 En solitario: Cubillos, Luis. "Delincuencia: Problema biológico-social y legal”. Revista de Ciencias Penales, t. I, 1935, p. 146-153, 324-332 y p. 488-498; "La realidad médico-social de nuestra población carcelaria”. Revista de Ciencias Penales, t. VI, 1942, p. 391-395.

${ }^{34}$ Agüero C., Guillermo. "Aspectos de nuestra delincuencia femenina”. Revista de Ciencias Penales, t. IV, 1938, p. 61-78; "Análisis de la 'pequeña delincuencia' en Chile”. Revista de Ciencias Penales, t. V, 1941, p. $61-78$

35 Brandeau Galindo, Valentín. De la Represión y Prevención del Delito en Chile. Santiago: La Ilustración, 1917, 293. Su memoria de grado fue: Brandeau Galindo, Valentín. Política Criminal Represiva. Santiago: Imprenta Cervantes, 1909, $201 \mathrm{p}$.

36 Brandeau Galindo, Valentín. "Introduccción al Estudio del Derecho penal”. Revista de Ciencias Penales, t. I, 1935, p. 122-137 y 302-317. El anuncio de enfermedad del autor está en el $\mathrm{N}^{\circ} 5$ de ese año.

37 Gajardo, Samuel. Medicina Legal. Santiago: Nascimento, 1931 (1 $1^{\mathrm{a}}$ ed., 353 p.) y 1939 (2 ed., 2 t., 413 y 428 p.). Es en el t. II donde Gajardo declara "la insuficiencia" de la Escuela Clásica y defiende los postulados positivistas, rescatando la tradición lombrosiana, adaptada a los progresos de la psicología y endocrinología de la época como guías para determinar la "génesis del delito" y, por tanto, las mejores vías para su prevención y represión. Autor prolífico, Gajardo, quien se desempeñó simultáneamente como Profesor de extraordinario de Derecho Penal y titular de Medicina Legal en la Escuela de Derecho de la Universidad de Chile y como Juez de Menores, aparte de su texto de Medicina Legal, dedicó sus obras a temas principalmente relativos a los aspectos de su ejercicio jurisdiccional, lo que seguramente ha incidido en su completo olvido hoy en día. Entre esas obras se pueden mencionar: Justicia con alma. Santiago: Imp. Prisiones, 1926; Los derechos del niño y la tiranía del ambiente. Santiago: 1929, 179 p.; Delincuencia infantil. Santiago: Imp. Prisiones, 1940, 294 p.; Memorias de un Juez. Santiago: 1957, 222 p.; Protección de menores. Santiago: Ed. Jurídica de Chile, 1955, 124 p. Otros textos, desvinculados del cargo de Magistrado, y donde es posible ver manifiesta su asociación al positivismo, son: "Conceptos modernos de Derecho penal". Revista de Derecho y Jurisprudencia, t. III, 1934, p. 33-36; Ensayo sobre el hombre antisocial. Santiago: Cervantes, 1942, 130 p.; La vida sexual ante el Derecho. Santiago: Cervantes, 1944, 158 p.; Reflexiones sobre la pena de muerte. Santiago: Universo, 1946, 88 p.

${ }^{38}$ Una exposición de su vida y obra, no completamente lograda, puede verse en Espinoza H., Mauricio. Gustavo Labatut Glena: vida, obra y aporte al Derecho penal actual. Tesis UTALCA. Dir.: J.P. Matus A. Talca, 2005, 65 p. 
determinar la pena "teniendo en cuenta el grado de peligrosisdad que revela el delincuente" (Art. 44); especialmente para hacer las rebajas y aumentos por atenuantes y agravantes "que denotan, respectivamente, que el delincuente no es peligroso o que lo es" (Art. 47); e incorporar las medidas de seguridad de duración indeterminada en recintos de salud o en colonias penales como sanciones para inimputables (Art. 59), delincuentes "de imputabilidad disminuída que por sus condiciones psíquicas aparezca como socialmente peligroso" (Art. 60), "alcohólicos o toxicómanos crónicos” y "dipsómanos" (Art. 61), "vagos y mendigos" (Art. 62), "reincidente[s] que haya[n] sido condenados anteriormente más de tres veces y manifieste[n] inclinación al delito, a la vagancia o mendicidad" (Art. 63); así como medidas de suspensión condicional de la pena (Arts. 76 a 78) y libertad condicional (Arts. 79 a 83), basadas en escasa la peligrosidad del condenado. ${ }^{39}$ Sin embargo, esta influencia persistió sólo hasta la primera edición de su Manual de Derecho penal (1948), donde dedica extensos párrafos a la criminología y a las escuelas penales; ${ }^{40}$ diez años después, como anuncia en el Prólogo de la tercera edición, ya considera esos párrafos "de importancia secundaria", mostrando una marcada inclinación por la "escuela técnico-jurídica”, que "depura al derecho penal de las infiltraciones filosóficas con que los clásicos la desvirtuaron, y de las concepciones biosociológicas de los positivistas". ${ }^{41}$

Al igual que en el caso de Labatut, Rafael Fontecilla ${ }^{42}$ transitó desde el positivismo hacia la dogmática, aunque dado que su positivismo era un derivado de la Escuela de Política Criminal de von Liszt, ${ }^{43}$ como se ve reflejado en el Proyecto de Código Penal presentado en coautoría con Eduardo Erazo (1929), donde aunque se declaraba que "lo más eficaz habría sido la aceptación amplia de la fórmula del estado peligroso, como fundamento único de la medida de la pena y límite de las responsabilidad”, en definitiva se establecía un sistema vicarial con penas para imputables y medidas de seguridad para imponer sanciones a quienes, sin cometer delitos, pudieran considerarse peligrosos

${ }^{39}$ Una detallada exposición de estas medidas puede verse en Labatut Glena, Gustavo. "La peligrosidad de las personas naturales en el Proyecto de Código Penal Chileno”. Revista de Ciencias Penales, t. IV, 1938, p. 289-296. El Proyecto se encuentra en el mismo lugar, p. 79-192. Observaciones críticas al mencionado Proyecto, en lo que respecta a los "delitos contra la propiedad", pueden verse en el mismo tomo de la Revista de Ciencias Penales, efectuadas por Federico Peña C. (p. 379-393 y 465-470).

${ }^{40}$ Labatut Glena, Gustavo. Manual de Derecho penal. Santiago: s/e, 1948, 551 p., donde habla, siguiendo a Ferri, de que "hoy en día se considera a la escuela clásica en completa bancarrota, porque ha sido impotente para contener el aumento de la criminalidad, especialmente en dos de sus formas: reincidencia y delincuencia infantil" (p. 46) y afirma, junto a los positivistas, que "el delito es fundamentalmente un hecho del hombre que se realiza en el seno de la sociedad" (p. 47) y llama a Lombroso, ya desmitificada su tesis del "criminal nato", "el verdadero creador del derecho penal moderno, porque a él se debe la idea de sistematizar las investigaciones penales tomando como punto de partida la persona del delincuente, que es una realidad, en sustitución de la abstracción del delito" (p. 20).

${ }^{41}$ Labatut Glena, Gustavo. Manual de Derecho penal, t. I. $3^{\text {a }}$ ed. Santiago: Ed. Jurídica de Chile, 1958, 480 p., p. 13.

${ }^{42}$ Sobre su trayectoria científica, consúltese Cabello de la Fuente, Carlos. Rafael Fontecilla Riquelme. Vida, obra e influencia en el Derecho penal chileno. Tesis UTALCA. Dir.: J.P. Matus. Talca, 2005, 60 p.

43 Politoff / Matus / Ramírez, Lecciones PG, p. 36. 
(inimputables, "malvivientes” y "delincuentes crónicos”), junto a otras medidas prácticas para evitar las penas cortas de prisión (remisión condicional de la pena, perdón judicial y multas). ${ }^{44}$ El paso hacia una "técnica jurídica" marcadamente influenciada por la dogmática penal alemana fue, de este modo, natural, llegando a considerarse a Fontecilla el primer introductor en Chile del concepto de "tipo penal", en la fórmula de Beling, ${ }^{45}$ aparte de legarnos obras tan sofisticadas como su Concursos de delincuentes, de delitos y de leyes penales y sus principales problemas jurídicos, de 1956, en donde abundan las citas de Berner, v. Buri, Liszt, Schmid, Mezger, Honig, M. E. Mayer, Frank y Beling. ${ }^{46}$

\subsection{El epígono del positivismo nacional: Raimundo del Río}

Pero, como al principio anunciamos, el principal de nuestros positivistas fue Raimundo del Río, ${ }^{47}$ quien ya había dado un destacado tratamiento a la Escuela Positiva en las "notas tomadas en clase del profesor Señor don Ricardo Cabieses" (1915), ${ }^{48}$ adhiriendo abiertamente a ella al año siguiente en su memoria de grado sobre "El Problema Penal", $(1916)^{49}$ donde afirmaba:

${ }^{44}$ Fontecilla R., Rafael. La pena. Santiago: Cisneros, 1931, 420 p. El texto del proyecto se encuentra en su "Apéndice".

${ }^{45}$ Fontecilla R., Rafael. "El concepto jurídico de delito y sus principales problemas técnicos". Revista de Ciencias Penales, t. II, 1936, pp. 21-51, en particular la p. 34, y su afirmación posterior de que "el primer deber del juez instructor es establecer la existencia del tipo (cuerpo del delito) según nuestro derecho procesal" (p. 38). Antes, en su homenaje póstumo a Beling, ya había expuesto ideas similares ("Geheimrat". Anales de la Universidad de Chile. Primer trimestre, 1933, p. 41-52).

${ }^{46}$ Fontecilla R., Rafael. Concursos de delincuentes, de delitos y de leyes penales y sus principales problemas jurídicos. Santiago: Editorial Jurídica de Chile, 1956, 121 p. Los tres artículos que componen esta obra fueron primero publicados como "Apartados” de la Revista Penal de Buenos Aires, entre 1945 y 1946.

${ }^{47}$ Según se señala en la memoria de grado de Jaque A., Paulina. José Raimundo del Río. Vida, obra e influencias en el Derecho penal. Tesis UTALCA. Dir.: J.P. Matus. Universidad de Talca, 2005, 71 p., p. 5-13, Raimundo del Río inició su carrera como profesor de Derecho Penal de la Universidad de Chile en 1918, apenas dos años después de titulado, dictando simultáneamente el curso de Medicina Legal, de manera casi ininterrumpida, hasta su jubilición, 38 años después, en 1956. Su mayor productividad científica es del período comprendido entre 1916 y 1945. A partir del año 1946 asume, hasta su jubilación en 1956, el Decanato de la Facultad de Derecho de la Universidad de Chile, período en que sus esfuerzos derivan hacia la administración universitaria y la creación y consolidación de la Editorial Jurídica de Chile, que hasta hoy le sobrevive.

${ }^{48}$ Del Río, Raimundo. Derecho penal. Notas tomadas en clase del profesor Señor don Ricardo Cabieses. Santiago: Imp. Universitaria, 1915, 51 p., de las cuales 20 se dedican a la "Escuela Positiva" (p. 30-51). Sin embargo, como puede verse en las "notas" tomadas por otros discípulos de Cabieses, éste se limitaba a la exposición de la doctrina de Ferri, para luego hacer un análisis de derecho vigente, "concretándonos no solamente a su estudio exejético, sino que examinando en lo posible la relación que existe entre los 105 primeros artículos i la doctrina de Derecho Penal que ha inspirado a nuestros lejisladores al dictarlos i que no es otra que la doctrina de la Escuela Clásica” (Belmar, Roberto; Gandulfo, Pedro; Guerrero, Juan. Derecho penal. Apuntes tomados en clase de don Ricardo Cabieses, ampliados y redactados. Santiago: Imp. Estrella del Pacífico, 1918, 223 p., p. 93).

${ }^{49}$ Del Río, Raimundo. El problema penal. TU. Santiago, Imp. Univ., 1916, 104 páginas. 
"Las instituciones penales de los pueblos modernos adolecen de dos graves defectos: no conseguir la finalidad de su fundación, i estar basadas en principios científicos y filosóficos antiguos, que hicieron su época, que produjeron su efecto, i acaso pudieron deslumbrar al mundo en el momento de su concepcion, pero que están mui léjos de guardar armonía con las últimas conquistas de la ciencia [... La criminalidad se desarrolla; la reincidencia i la precocidad en los ajentes del delito son cada dia mayores; la lei es impotente para reprimirlas, aun para aminorarlas: manifestaciones son éstas que muestran claramente cuan infructuosos han sido los esfuerzos de las viejas escuelas de derecho penal para solucionar el problema". ${ }^{0}$

Siguiendo las enseñanzas de Letelier, propuso Del Río algunos años después extender la adopción del método positivo a la investigación y enseñanza del Derecho en general, estudiando no solamente "su formación originaria y su organización actual", sino también "las causas sociales de su nacimiento y la ley de su progreso", para lo cual sugiere recurrir no sólo a la observación e inducción de los hechos históricos y estadísticamente demostrables, sino también del método comparativo entre diversos pueblos, para determinar el carácter local o universal de las instituciones. Este método permitiría "convertir al estudiante en verdadero constructor de la ciencia emancipándole de la autoridad del maestro" y, al mismo tiempo, extirpar "de raíz en el profesorado universitario la tendencia anticientífica de formar escuelas y sectas con doctrinas subjetivas más o menos impugnables". 51

En cuanto al Derecho penal en particular, en su memoria de prueba (1916) Del Río hace suyas las siguientes “conclusiones” de la Escuela Positiva, marcadamente en la línea "antropológica” de Lombroso:

“ 1 a . La escuela positiva no admite el libre albedrío como fundamento de la responsabilidad moral; $2^{a}$. El estudio de la antropolojía demuestra que los delincuentes presentan anomalías orgánicas, psicolójicas i morales que los distinguen de los demás hombres; $3^{\mathrm{a}}$. El estudio de la estadística demuestra que las penas por sí solas no bastan a disminuir la delincuencia". ${ }^{52}$

Veinte años después, en su Derecho penal (1935), Del Río destaca más aspectos sociológicos en su forma de entender el positivismo, señalando que los postulados básicos serían:

"1 ${ }^{\circ}$. El delito es el producto de las condiciones físicas y psíquicas del hombre y de factores naturales, sociales y económicos que lo determinan; $2^{\circ}$. El libre albedrío no existe $y$, en consecuencia, es necesario fundar en otra base la imputabilidad de los

${ }^{50}$ Del Río, El problema..., p. 3.

51 Del Río, Raimundo. "Clase Inaugural del Curso de Derecho Penal de la Universidad de Chile". Revista de Derecho, t. XVII, N's 1-2, marzo-abril de 1920. p. 18-26, p. 25.

52 Del Río, El problema..., p. 40. Las p. 41-90 de esta oba se dedican a desarrollar estos postulados. 
hechos delictuosos; y $3^{\circ}$. La pena no basta por sí sola para combatir la criminalidad; y su mero concepto expiatorio no puede satisfacer a la ciencia penal". 53

Finalmente, en sus Explicaciones de Derecho penal (1945) afirma que en cuanto a determinación del delito y de la pena,

"En realidad, no se trata solamente de valorizar determinados bienes y de idear ataques en contra suya que justifiquen una medida traducida en la ley penal. Es preciso pensar que esa valoración debe corresponder a un medio social dado; que dichos ataques son llevados a cabo, no por un ente abstracto, sino que por un hombre que vive en ese medio; y que la propia aplicación de la ley penal, en orden a alcanzar sus fines, exige la consideración de realidades ajenas a las normas que las inspiran y a los textos que las traducen". 54

Sin embargo, acepta que la determinación de la responsabilidad penal o los fundamentos de la imputación, en palabras actuales, conforme a la ley, puede hacerse estableciendo los "elementos del delito" según la que denomina "técnica contemporánea" (y que nosotros denominaríamos dogmática penal neokantiana): a) acción, omisión y "acción por omisión"; b) los "vínculos de causalidad"; c) la "tipicidad" y la "antijuridicidad"; y d) la "culpabilidad"; 55 pero afirma que ese estudio es sólo parte del "aspecto legal" del Derecho penal, al que debe sumársele la investigación de las causas individuales y sociales del delito, aspectos “antropológico" y "sociológico”, respectivamente, y aún un aspecto "político", esto es, "la determinación de las instituciones adecuadas para la lucha contra la criminalidad". ${ }^{56}$ Estos últimos aspectos resultan especialmente relevantes a la hora de estudiar la reacción social al delito, pues

"La pena no basta por sí sola para defender a la sociedad contra el delito. La historia ofrece numerosos ejemplos de la ceguera de los hombres aplicando castigos, muchas veces ponderados y monstruosos, con resultados negativos; la estadística demuestra que la reincidencia y la precocidad en los agentes del delito son cada día mayores, hechos que prueban la impotencia de la pena en la solución del problema; y la lógica dice que no es posible esperar de una fuerza principalmente psicológica, como es la pena, el éxito debido contra factores tan variados y complejos como son los que generan el crimen. Las medidas propiamente penales deben ser complementadas con medidas preventivas, curativas, eliminatorias y con las denominadas medidas de seguridad". 57

\footnotetext{
53 Del Río, Raimundo. Derecho penal, t. I. Santiago: Nascimento, 1935.320 p., p. 212.

${ }^{54}$ Del Río, Raimundo. Explicaciones de Derecho penal, t. II. Santiago: Nascimento, 1945. 366 p., p. 324.

55 Del Río, Raimundo. Explicaciones de Derecho penal, t. I. Santiago: Nascimento, 1945. 344 p.,

${ }^{56}$ Del Río, Raimundo. Explicaciones, t. II, p. 290.

57 Del Río, Raimundo, Explicaciones, t. I, p. 290.
} p. 234-283. 


\section{La "Lucha De las Escuelas" y El DeClive Del Positivismo ENTRE LOS PENALISTAS CHILENOS}

El primer artículo del número uno del tomo primero de la Revista de Ciencias Penales, del año 1935, se titula "El estado peligroso", y en él el entonces profesor de Derecho penal de la Universidad de Chile Alfredo G. Bravo da cuenta del estado de la llamada "lucha de las escuelas", calificándola de "discusión e interminable", que más que mejoras en la legislación y en el control de la criminalidad sólo había generado "una exhuberante bibliografía de controversia"; proponiendo concentrar los esfuerzos de la investigación en "un nuevo objeto de análisis: el hombre peligroso", esto es, el individuo "en cuanto sus actividades físicas, intelectuales o morales implican consecuencias que lesionan el derecho de los demás", respecto del cual "es la propia defensa, surgida en satisfacción del inalienable instinto de conservación, el fundamento real y único del derecho que autoriza al conjunto de individuos socializados para contrarrestar[lo]". ${ }^{58}$ Este enfoque, que el propio Bravo califica de "Derecho de la Defensa Social", llega en sus efectos prácticos a las mismas conclusiones básicas que el positivismo:

" $1^{\circ}$. Abolición del sistema de responsables e irresponsables.- La ley cautela la integridad de la fórmula social y, por lo tanto, extiende su acción sobre todo el que la amenace o perturbe (peligroso) sea o no moralmente culpable.

$2^{\circ}$. Abolición del sistema punitivo propiamente tal, es decir, retributivo y expiatorio.- La ley no castiga, sólo previene, corrige o elimina en nombre de la defensa social". 59

Sin embargo, la discusión, al menos en Chile, no había acabado del todo: el siguiente artículo de este número inicial de la Revista de Ciencias Penales es de Pedro Ortiz Muñoz, quien enfrentado al tema de "Los Problemas de la Reforma Penal" sugiere a los reformadores que "abandonen los prejuicios que los liguen demasiado al pretérito, pero que, al mismo tiempo, resistan con patriótica entereza a esa avalancha imprudente e irreflexiva que se llama avanzada", en abierta alusión al positivismo y sus variantes. ${ }^{60} \mathrm{Ya}$ antes, en sus Nociones de Derecho Penal (1933), Pedro Ortiz se manifestaba contrario a la "literatura italiana y española que abunda en estas tierras" y partidario del estudio del derecho penal siguiendo el modelo de la dogmática alemana representada en las obras de v. Liszt, Kramer y Frank, ${ }^{61}$ de cuya traducción se sirve al punto que, con justicia, Jiménez de Asúa califica estas Nociones de "calco del Tratado de Franz von Liszt", ${ }^{62}$ lo

${ }^{58}$ Bravo, Alfredo G. "El estado peligroso". Revista de Ciencias Penales, t. I, 1935, p. 5-12, p. 5,7 y 8.

${ }^{59}$ Bravo, "El estado peligroso", p. 8.

${ }^{60}$ Ortiz Muñoz, Pedro. "Los Problemas de la Reforma Penal”. Revista de Ciencias Penales, t. I, 1935, p. $13-15$, p. 15 .

${ }^{61}$ Ortiz Muñoz, Pedro. Nociones Generales de Derecho Penal, t. I. Santiago: Nascimento, 1933, 226 p., p. 5 a 7. Otras obras generales del autor son: Nociones de Derecho Penal, t. II. Santiago: Nascimento, 1937, 214 p.; y Curso Breve de Derecho penal, común y militar. Santiago: Imp. Carabineros de Chile, 1947. p. 1181.

62 Jiménez de Asúa, Luis. Tratado de Derecho penal, t. I. $5^{\text {a }}$ ed. Buenos Aires: Losada, 1950, 1435 p., 
que parece aplicable al conjunto de sus obras generales, con el mérito, si se quiere, de que el propio Ortiz Muñoz lo reconoce sin tapujos y con humildad. ${ }^{63}$

Pero no estaba Ortiz Muñoz solo ante un "ambiente totalmente conquistado por la Escuela Positiva, cuyos dioses Lombroso, Ferri y Garófalo emitían destellos que deslumbraban y enceguecían a quienes pretendían recorrer en Chile la senda áspera del Derecho penal", como se señala en una reseña de su pensamiento hecha como homenaje póstumo. ${ }^{64}$ Ya hemos dicho que desde principios del siglo XX Ramón Cabieses defendió en sus clases una aproximación exegética al Derecho Penal, siguiendo los principios de la Escuela Clásica; ${ }^{65}$ y aunque el carácter marcadamente positivista y criminológico de los tomos de la Primera Época de la Revista de Ciencias Penales (1935 a 1940) es indesmentible, si se estudia entre los "artículos originales" la proporción de títulos "positivistas" en relación con los "técnicos”, puede verse que mientras en el tomo I (1935) ésta era de 22 a 4 (pero dos eran extranjeros y los nacionales, ambos de un mismo autor: Federico Peña); ${ }^{66}$ en el tomo II (1936), de 8 a 5 (junto a dos extranjeros, aparecen ya tres nacionales: Drapkin, ${ }^{67}$ Peña ${ }^{68}$ y Fontecilla, quien declara terminada la "Lucha de Escuelas", y que "los principales problemas del derecho penal están centrados, más que en divagaciones de tipo social, en estudios de técnica); ${ }^{69}$ en el tomo III (1937), de 7 a 5 (con un extranjero, una continuación de Peña, ${ }^{70}$ otra de Drapkin ${ }^{71}$ y artículos de Vicuña ${ }^{72}$ y Schweitzer); ${ }^{73}$ en el tomo IV (1938) la tendencia vuelve a decantarse claramente a favor

${ }^{63}$ Abarza Y., René. Pedro Pablo Ortiz Muñoz. Vida, obra e influencia en el Derecho penal chileno. Tesis UTALCA. Dir.: J.P. Matus. Talca, 2005, 55 p., p. 53.

${ }^{64}$ Montero Schmidt, Mario. "El pensamiento jurídico penal de Pedro Ortiz". Revista de Ciencias Penales, t. X, No 2, 1948, p. 110 y siguiente.

65 Ver nota al pie $\mathrm{N}^{\circ} 48$.

66 "Del robo con homicidio" y "La confesión como medio de prueba". Revista de Ciencias Penales, t. I, 1935, p. 21-28 y 296-301.

${ }^{67}$ Drapkin, "Enajenación mental”.

${ }^{68}$ Peña, Federico. "El poder de policía y la prevención del delito". Revista de Ciencias Penales, t. II, 1936 , p. 108-113, 229-239 y 553-561.

${ }^{69}$ Fontecilla, "Concepto”, p. 22. Sin embargo, todavía en este momento consideraba Fontecilla que "la sentencia indeterminada, y la defensa social y la peligrosidad del delincuente ... son, sin duda las bases capitales del nuevo edificio jurídico-penal”, a lo que agrega: "pero volver a insistir sobre estas teorías ya tan conocidas y desenvueltas, es producir jadeo y no quiero cansar al lector".

${ }^{70}$ Peña, Federico. "El poder de policía y la prevención del delito". Revista de Ciencias Penales, t. III, 1937, p. 342-359.

${ }^{71}$ Drapkin, "La menor edad".

72 Vicuña S., Luis. "Observación al régimen procesal de los menores”. Revista de Ciencias Penales, t. III, 1937 , p. 198-232. Se debe aclarar, con todo, que se trata sólo de un oficio de un Juez de Menores a la I. Corte de Apelaciones de Valparaíso, donde se entremezclan diversas cuestiones prácticas, más allá de los problemas procesales jurídicos.

73 Schweitzer S., Miguel. "El delito de acusación o denuncia calumniosa". Revista de Ciencias Penales, t. III, 1937 , p. 342-359. Antes, ya había expresado su tendencia hacia el tecnicismo jurídico en un muy interesante comentario a una sentencia aparecido en el tomo I, donde discute acerca del significado de la expresión "voluntaria" en el art. 1 del Código penal ("Marginando una sentencia". Revista de Ciencias Penales, t. I, 1935, p. 197-199). 
del positivismo, con una proporción de 18 a 6 (aparecen, entre los técnicos, Valdovinos, ${ }^{74}$ Drapkin (2), ${ }^{75}$ Alessandri y Benavente, ${ }^{76}$ Schweitzer $^{77}$ y Peña) $;^{78}$ en cambio, después de un receso de tres años, en el primer tomo de la Segunda Época (tomo V, 1941), la tendencia ya es contraria: 9 artículos de "técnica-jurídica" (tres extranjeros y los de Fontecilla, ${ }^{79}$ Varas, ${ }^{80}$ Alessandri, ${ }^{81}$ Marín, ${ }^{82}$ Fontecilla A., ${ }^{83}$ y Ortiz Muñoz), ${ }^{84}$ frente a una varia de criminalística e informaciones donde aparecen sólo cinco artículos de verdadera criminología positivista, ninguno escrito por juristas chilenos.

Es la existencia de este grupo de autores y profesores universitarios la que mantiene una suerte de "resistencia" frente a los "destellos" emanados de los "dioses" del positivismo, lo que explica que también antes de 1940 se siguieran no sólo publicando alegatos forenses de corte marcadamente técnico-jurídico, ${ }^{85}$ sino también memorias de grado de igual orientación, como lo expresan, entre otros, los siguientes títulos: Del concepto jurídico del delito (1941), ${ }^{86}$ La tentativa y el delito frustrado (1923), ${ }^{87}$ El concurso de delincuentes (1929), ${ }^{88}$ Concurso o acumulación de delitos (1935), ${ }^{89}$ La responsabilidad penal del

${ }^{74}$ Valdovinos, Carlos. "El delito de incendio con fines de lucro". Revista de Ciencias Penales, t. IV, 1938, p. 12-35.

75 Drapkin, "Defensa legítima” y "Uxoricidio".

${ }^{76}$ Alessandri R., Arturo; Benavente, Darío. "El recurso de casación en materia penal en la legislación chilena". Revista de Ciencias Penales, t. IV, 1938, p. 36-60.

77 Schweitzer, Miguel. "Síntesis de la legislación chilena de menores". Revista de Ciencias Penales, t. IV, 1938, p. 310-316.

78 Peña C., Federico. "Observaciones al nuevo Proyecto de Código Penal”. Revista de Ciencias Penales, t. IV, 1938, p. 379-393 y 465-470.

${ }^{79}$ Fontecilla, Rafael. "El juicio penal”. Revista de Ciencias Penales, t. V, 1941, p. 7-23.

${ }^{80}$ Varas V., Eduardo. "Comunicabilidad a los co-delincuentes de los elementos constitutivos de un delito”. Revista de Ciencias Penales, t. V, 1941, p. 49-56.

${ }^{81}$ Alessandri R., Fernando. "La condena por perjuicios en el proceso penal". Revista de Ciencias Penales, t. V, 1941, p. 103-110.

${ }^{82}$ Marín, Urbano. "La libertad condicional en Chile". Revista de Ciencias Penales, t. V, 1941, p. 206-240.

${ }^{83}$ Fontecilla A., Juan. "La apelación del sobreseimiento definitivo en el Código de Justicia Militar". Revista de Ciencias Penales, t. V, 1941, p. 333-340.

${ }^{84}$ Ortiz Muñoz, Pedro. "Voluntariedad y otras cuestiones". Revista de Ciencias Penales, t. V, 1941, p. 372-388.

${ }^{85}$ Entre otros, famosos son los alegatos de Lazo, Santiago. El Crimen de Lo Vicuña. Santiago: Universo, 1921, 141 p.; y Gallardo Nieto, Galvarino. Defensa del Canódromo de Beneficencia ante la Excma. Corte Suprema. Santiago: La Ilustración, 1935, 224 p.

${ }^{86}$ Cabrera B., Gonzalo. Del concepto jurídico de delito. Tesis UCH. Santiago: Leblanc, 1941, 78 p.

${ }^{87}$ Donoso H., Óscar. La tentativa y el delito frustrado. Tesis UCH. Santiago: Inglesa, 1923, 119 p.

${ }^{88}$ Cooper A., Federico. El concurso de delincuentes. Tesis UCH. Santiago: Artes y Letras, 1929, 82 p. En la misma línea: Almarza P., Olga. El delito de encubrimiento. Tesis UCH. Santiago: Rapid, 1941, 53 p.

${ }^{89}$ Manríquez C., Carlos. Concurso o acumulación de delitos. Tesis UCH. Santiago, 1935, 143 p. 
médico (1939), ${ }^{90}$ El delito de lesiones (1939), ${ }^{91}$ El delito de apropiación indebida (art. $470 \mathrm{~N}^{\circ}$ 1 del Código penal) (1937), ${ }^{92}$ y otras memorias de parte especial ${ }^{93}$ y procesal penal. ${ }^{94}$

Sin embargo, no sólo hubo resistencia en el mundo universitario al positivismo, sino también en el político: no se aprobó ninguno de los Proyectos de Código penal basados en dicha doctrina y la aprobación en 1949, a instancias del Instituto de Ciencias Penales, de la Ley $\mathrm{N}^{\circ} 11.625$, sobre "estados antisociales y medidas de seguridad”, que establecía un "sistema dualista" de medidas de seguridad pre y postdelictuales, fue más bien una victoria pírrica: nunca llegaron a entrar en vigencia las disposiciones que regulaban tales estados y medidas, pues no se construyeron los lugares de detención, casas de trabajo y colonias agrícolas que se preveían para ello. ${ }^{95}$ Sólo el Proyecto de Ley para establecer la "remisión condicional de la pena", impulsado también por el Instituto de Ciencias Penales, como herramienta para "evitar el contagio moral de los delincuentes primarios del tipo ocasional” -según reza su Mensaje-, logró superar las barreras de la legislación, convirtiéndose primero en la Ley $\mathrm{N}^{\circ} 7.821$, de 29 de agosto de $1944^{96}$ y, después, en la Ley $\mathrm{N}^{\circ} 18.216$, de 18 de enero de 1984 , actualmente en vigor. ${ }^{97}$

Otra causa, menos glamorosa si se quiere, del declive del positivismo en Chile y en toda Latinoamérica antes de llegar a la medianía del siglo XX, era muy bien explicada por Jiménez de Asúa en 1950, y sobran palabras para comentarla:

"En casi todas partes, los positivistas se hacen -valga la frase- escolásticos, y citan a Ferri y a Garofalo como podían invocar los nombres de Carrara o de Berner. No investigan la realidad delincuente, ni estudian las características del criminal ni las causas del delito. Sólo citan lo que hicieron, más de medio siglo ha, los revolu-

${ }^{90}$ Alcayaga V., Marta. La responsabilidad penal del médico. Tesis UCH. Valparaíso: Royal, 1939, 69 p.

${ }^{91}$ Espinoza S., Claudio. El delito de lesiones. Tesis UCH. Santiago: Manila, 146 p. Antes: Aguirre, Santiago. De las lesiones. Tesis UCH. Santiago: Comercial, 1922, 56 p.

${ }^{92}$ Ballivián H., José. El delito de apropiación indebida (art. $470 N^{\circ} 1$ del Código penal). Tesis UCH. Santiago: La Gratitud, 1937, 67 p. En la misma clase de delitos, véase: Acevedo H., Amador. Del abuso de firma en blanco. Tesis UCH. Santiago: El Imparcial, 76 p.

93 Alsina A., Javier. El delito de prevaricación. Tesis UCH. Chillán: Alsina, 109 p.; Orrego V., Germán. Delitos de imprenta o de publicación. Tesis UCH. Santiago, 1937, 182 p.; y Aguirre G., Manuel. De los delitos contra la seguridad interior del Estado. Tesis UCH. Santiago: La Nación, 1932, 134 p., entre otras.

${ }^{94}$ Rencoret D., Raúl. De la confesión judicial y especialmente de su divisibilidad e indivisibilidad. Tesis UCH. Santiago: La Ilustración, 1925, 54 p. Otra memoria de procedimiento penal de la época es la de Goyeneche P., Raúl. ¿Pueden querellarse las personas jurídicas? Tesis UCH. Santiago: La Compañía, 1929, 89 p.

${ }^{95}$ Sobre la historia y detalles de elaboración de estos Proyectos y de la Ley N ${ }^{\circ} 11.625$, ver Rivacoba y Rivacoba, Manuel. Evolución histórica del Derecho penal chileno. Valparaíso: EDEVAL, 1991, 151 p., p. 86-96 y $109-112$.

${ }^{96}$ Para una evaluación del funcionamiento de esta Ley, véase Gesche, Bernardo. La remisión condicional de la pena. Santiago: Editorial Jurídica de Chile, 1975, 314 p. Las conclusiones de este estudio afirman que la remisión condicional disminuye la probabilidad de reincidencia de los beneficiados (p. 101-107), con independencia de la longitud de la condena.

${ }^{97}$ Una evaluación del funcionamiento de esta ley puede verse en Hofer D., Ma Eugenia. "20 años de

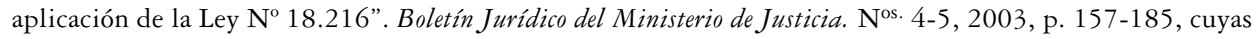
conclusiones son similares a las del estudio de la nota anterior. 
cionarios en su tiempo. Por eso puede afirmarse, sin temor a ser desmentidos, que no hay auténticos criminólogos en Hispanoamérica". 98

Naturalmente, sin investigación autónoma, no era (ni es actualmente) posible una auténtica ciencia que despierte el interés de discípulos que puedan profundizarla.

\section{LA herencia del positivismo EN LA ACTUALIDAD: EL CARÁCTER “PELIGROSISTA” DE NUESTRO SISTEMA PENAL}

Como ya lo anunciáramos, si dejamos de lado el renacer de la criminología positiva en esta última década, ${ }^{99}$ pareciera que no existiera en nuestra doctrina actual ningún defensor de las tesis positivistas, o al menos ninguno que lo sea al modo que se la defendía y propagaba en los primeros años del siglo XX.

Sin embargo, más allá de las declaraciones solemnes, podemos intentar contrastar las tesis centrales del positivismo allí donde en la doctrina predominantemente "dogmática" o "técnica-jurídica" debieran tener una respuesta diferente. Para ello es importante tener en cuenta que, en su última versión, Del Río no rechaza la necesidad de la "dogmática" a la hora de estudiar los fundamentos de la responsabilidad penal, sino sólo le otorga un valor menor, de "técnica-jurídica", que debe ser complementado con consideraciones sociológicas, antropológicas y políticas, principalmente a la hora de determinar las formas de reacción social.

\subsection{Primera tesis: negación del libre albedrío y de la imputabilidad como presupuesto de la reacción social}

Hoy en día, con diversos matices, parece que la mayor parte de la doctrina está de acuerdo en que no es posible encontrar el fundamento de la responsabilidad penal en la libertad moral o libre albedrío al estilo de los autores clásicos, ${ }^{100}$ sino a lo más en una suerte de libertad relativa al hecho de vivir en sociedad, como estructura comunicacional básica de lo que denominamos "derecho" y "sociedades democráticas". ${ }^{101}$ Cury agrega que la libertad es indemostrable y sólo se afirma como una "pura hipótesis de trabajo, a la cual, de acuerdo con el estado actual de nuestros conocimientos, parece razonable atribuir consecuencias mejores que a la tesis antagónica" (responsabilidad penal basada en la peligrosidad), aunque las consecuencias de esta hipótesis (los casos en que se considera

\footnotetext{
98 Jiménez de Asúa, Luis. Tratado de Derecho penal, t. II. $5^{a}$ ed. Buenos Aires: Losada, 1950, 1439 p.,

${ }^{99}$ Ver nota al pie $\mathrm{N}^{\circ} 9$.

100 Aunque así lo afirma todavía Garrido Montt, Mario. Derecho penal. Parte general. Nociones fundamentales de la Teoría del Delito, t. II. $3^{a}$ ed. Santiago: Editorial Jurídica de Chile, 2003. 358 p., p. 198.

101 Politoff / Matus / Ramírez, Parte General, p. 243, nota 183. Antes, Novoa, Curso, t. I, p. 433, con
} p. 82 . cita a Mezger. 
o no libre -iresponsable penalmente!- a una persona) deban estimarse, "por supuesto”, como "una ficción", aunque justificada. ${ }^{102}$

No es este el lugar para establecer los efectos que semejante escepticismo debiera tener en la estructura de la teoría del delito, Gimbernat ya lo hizo, ${ }^{103}$ sino sólo para destacar que el reemplazo de la libertad de decisión por las teorías normativas de la culpabilidad basadas en esa resignada idea social de la libertad podría considerse un simple recurso para evadir el problema, como lo anticipaba el propio Del Río, ${ }^{104}$ e incluso como una salida en falso del mismo, según se deduce de la opinión de Etcheberry de que todos los elementos de la culpabilidad siguen teniendo un sustrato fáctico, incluyendo la idea de la libertad de decisión, con independencia del nombre con que se designen. ${ }^{105}$

Por otra parte, y precisamente respecto de la derivación de esta tesis positivista en el sentido de que la "imputabilidad" en sentido amplio no debería considerarse como fundamento para la imposición de reacciones sociales (penas o medidas), el triunfo del positivismo en la práctica es indiscutible: desde el sistema vicarial que rige la imposición de medidas de seguridad a los inimputables por enajenación mental respecto de los cuales existan "antecedentes calificados que permitan presumir que atentará contra sí mismo o contra otras personas” (arts. 455 a 464 Código procesal penal), hasta el sistema de la nueva Ley de Responsabilidad Penal del Adolescente, que impone sanciones a jóvenes desde los 14 años para "hacer efectiva la responsabilidad de los adolescentes por los hechos delictivos que cometan, de tal manera que la sanción forme parte de una intervención socioeducativa amplia y orientada a la plena integración social" (art. 20 Ley $\mathrm{N}^{\circ}$ 20.084), se fundamentan en la peligrosidad del autor, y no en su capacidad de delinquir, a la hora de determinar si y cuáles medidas son aplicables, como surge patente de la redacción del art. 455 del Código Procesal Penal, y está un poco más oculto en la del art. 24 de la Ley $N^{0} 20.084$.

Sin embargo, cuando en ese art. 24 de la Ley $\mathrm{N}^{\circ} 20.084$ (en concordancia con lo señalado en su art. 23) se mencionan la "gravedad del ilícito" (letra a)) y "la idoneidad de la sanción para fortalecer el respeto del adolescente por los derechos y libertades de las personas y sus necesidades de desarrollo e integración social" (letra f)), como "criterios" para determinar la sanción más adecuada para formar "parte de una intervención socioeducativa amplia”, no se está señalando otra cosa que indicadores objetivos (gravedad del hecho) y subjetivos (necesidad de desarrollo e integración social) de peligrosidad para la sociedad y el propio adolescente, claro que con palabras menos directas, y, por tanto, que dejan mayor ámbito de actuación discrecional a los tribunales (salvo en lo relativo a la gravedad del hecho, tasada en el art. 23). Lo anterior se complementa con la facultad de escuchar a peritos para determinar la pena, los que incluso pueden ser llamados directamente por el Tribunal, según el art. 40 de dicha Ley, y la facultad de

102 Cury. Derecho penal, p. 400.

103 Gimbernat O., Enrique. “¿Tiene un futuro la dogmática juridicopenal”. En Problemas actuales del Derecho penal y procesal. Salamanca, 1971, p. 87-109.

${ }^{104}$ Del Río, Explicaciones, t. I, p. 261.

105 Etcheberry. Derecho penal, t. I, p. 274-278. 
suspender el cumplimiento de tales medidas antes (art. 41) o durante su ejecución (art. 53), si con ello se logra mejor la finalidad de la integración social del infractor.

Sin embargo, no se ha llegado todavía a aceptar, siquiera por estas vías oblicuas, un "sistema binario", que permita la aplicación de medidas predelictuales, lo cual se prohíbe explícitamente en el art. 255 del Código Procesal Penal (que sólo permite imponer medidas a enajenados mentales que hubieren realizado al menos "un hecho típico y antijurídico"); e implícitamente en el art. $6^{\circ}$ de la Ley $\mathrm{N}^{\mathrm{o}} 20.084$, que sólo permite imponer las sanciones que contempla dicha ley "en sustitución de las penas contempladas en el Código penal y en las leyes complementarias”.

\subsection{Segunda tesis: el delito es un fenómeno que puede estudiarse causalmente}

En verdad, esta tesis no es negada por nadie hoy en día: sólo mantenemos la tranquilidad de espíritu que nos dan los fracasos de los estudios criminológicos pasados y los chistes que hacemos sobre la frenología y los estudios de Lombroso, considerando sin más la criminología como una "ciencia auxiliar" del derecho penal (en la esperanza de que nos auxilie lo menos posible). ${ }^{106}$

Sin embargo, por una vía inesperada, la "sociología criminal” al estilo Letelier y Ferri ha vuelto al centro del debate del derecho penal de la mano de la doctrina funcionalista adoptada por Jakobs, reconocidamente derivada de la teoría sociológica de Luhman sobre la función del derecho en la organización social, ${ }^{107}$ aunque sin pretensiones de ser comprobada en la realidad. ${ }^{108}$

La misma aparente indefensión de la doctrina tradicional ante las tesis funcionalistas que se plantean como "descriptivas" de la realidad social que se encarnaría el Derecho penal puede manifestarse si eventualmente la moderna criminología positiva, que ahora dispone del aparato matemático y estadístico de la economía y las ciencias sociales, reduce la supuesta indemostrabilidad del determinismo del comportamiento humano a la probabilidad mínima que se acepta como suficiente en las ciencias naturales para explicar el resto de los fenómenos causales. ${ }^{109}$

106 Politof / Matus / Ramírez. Lecciones PG, p. 87-90.

107 Jakobs, Günther. Strafrecht. Allgemeiner Teil. 2a ed. Berlin: De Gruyter, 1991, 944 p., p. 6, nota 8 al pie. Aunque con el paso del tiempo Jakobs ha variado en cierta medida sus planteamientos, como explica con claridad Silva Sánchez, Jesús Ma . "Del Derecho abstracto al Derecho "real”. Recensión a Günther Jakobs, La pena estatal: significado y finalidad (traducción y estudio preliminar de M. Cancio Meliá y B. Feijóo Sánchez), Thomson-Civitas, Madrid, 2006, 182 pág”. In Dret. 4/2006, Nº 377, p. 1-6, los fundamentos de la teoría sociológica sistémica en que se apoya parecen mantenerse inalterables en lo esencial.

${ }^{108}$ Dubber D., Markus. "Positive Generalprävention und Rechtsgutstheorie: Zwei zentrale Errungenschaften der deutschen Strafrechtswissenschaft aus amerikanischer Sicht". Zeitschrift für die gesamte Strafrechtswissenchaft, t. 117, 2005, p. 485-518, p. 415.

${ }^{109}$ Una visión panorámica de las orientaciones de los trabajos actuales en la materia puede verse en Cea, Macarena; Ruiz, Paulina; Matus, Jean Pierre. "Determinantes de la criminalidad: revisión bibliográfica". Polit. crim. No 2. D4, p. 1-34. 


\subsection{Tercera tesis: la pena es insuficiente para el control de la criminalidad}

Entre los efectos de esta tercera tesis del positivismo se cuenta la necesidad de establecer medidas de reacción social ante los hechos calificados de delitos diferentes a la imposición de las penas cuya medida esté basada en el grado de "reprochabilidad", ya sea como sustitutos o medidas fundadas en el grado de "peligrosidad" del autor, de manera que sean adecuadas para su integración a la sociedad o su neutralización, cuando ello no sea posible.

Entre nosotros, estas medidas fundadas en la "peligrosidad" del agente se encuentran desde hace tiempo recogidas en la Ley $\mathrm{N}^{\circ} 18.216$, sobre medidas alternativas a las penas privativas de libertad, y en el D.L. 321 de 1925 Sobre Libertad Condicional, y han cobrado nuevos bríos en las reglas contenidas en el Código Procesal Penal, que consagran el principio de oportunidad (art. 170), la suspensión condicional del procedimiento (art. 236) y la suspensión de la condena (art. 398). Por su parte, la Ley de Responsabilidad Penal de los Adolescentes transforma las penas en "medidas" y obliga considerar para su elección e imposición los efectos socioeducativos que ellas tendrían en la vida del adolescente, cuya imputabilidad a partir de los 14 años no se discute. También como pena "neutralizante" o inocuizante puede considerarse ahora la de presidio perpetuo calificado del art. 32 bis, dispuesta para poder eliminar la pena de muerte.

Sin embargo, si bien la pena de presidio perpetuo calificado no cuenta con el apoyo de la doctrina, y ella reclama contra la reincidencia como circunstancia agravante, las medidas de la Ley $\mathrm{N}^{\circ} 18.216$ y el cumplimiento de penas en libertad del DL 321 cuentan con su abierta aprobación: por eso en el Anteproyecto de Código Penal de 2005 se propuso la eliminación de las primeras y la mantención de las segundas. ${ }^{110} \mathrm{La}$ misma aprobación reciben, en general, los nuevos institutos procesales. ${ }^{111} \mathrm{Y}$ tanto las medidas alternativas a las penas privativas de libertad como las nuevas instituciones procesales tienen entre sus requisitos el que el condenado no sea reincidente y que su conducta anterior y posterior al delito permitan presumir que "no volverá a delinquir" o, dicho en clave positivista, todas ellas son alternativas a las penas previstas en la Ley, basadas en la "baja peligrosidad" del autor, esto es, en que se trata sólo de un "delincuente primario ocasional”, en las palabras que se usaban en la década de 1940.

Desde esa perspectiva, es posible una descripción del sistema de penas chileno, basada no en los criterios clásicos, como es habitual en los libros de texto, ${ }^{112}$ sino en la peligrosidad del autor, sistema cuya vigencia en la práctica diaria de los Tribunales está sobradamente comprobada en las estadísticas judiciales: del total de procedimientos ordinarios llevados adelante el año 2005, que terminaron "jurisdiccionalmente”, el 40\% terminó en "suspensión condicional del procedimiento", $9 \%$ en "acuerdos reparatorios”,

110 "Materiales de Discusión presentados a la Comisión Foro Penal, Parte General”. Polít. crim, No 1 , D2, p. 1-223, p. 162, 177 y 178.

111 Politoff / Matus / Ramírez. Lecciones PG, p. 579-581.

112 Por todos, Etcheberry. Derecho penal, t. II, p. 138 y siguientes. 
y en más de la mitad del $15 \%$ que terminó en sentencias condenatorias, la pena privativa de libertad fue sustituida por alguna de las medidas de la Ley $18.216(58 \%) .{ }^{113}$

Así, podemos decir que para los autores de baja peligrosidad la ley dispone de una batería de medidas que sustituyen a las penas privativas de libertad-algunas de las cuales pueden imponerse mediante "salidas anticipadas" del proceso sin necesidad de comprobar judicialmente su responsabilidad en los hechos, conforme a los requisitos propuestos por la "técnica" o "dogmática” jurídica, como sucede típicamente con la suspensión condicional y los acuerdos reparatorios (arts. 237 y 241 del Código Procesal Penal)-, ${ }^{114}$ mientras reserva para quienes muestran un "mayor grado de peligrosidad" la internación en prisiones u otras medidas de custodia de seguridad más o menos gravosas.

Los indicadores de peligrosidad del autor serían, simplificadamente hablando, dos: a) la gravedad o naturaleza del delito que se comete; y b) la conducta anterior y posterior al delito del condenado; y especialmente su "grado de compromiso delictual", medido por su calidad o no de reincidente.

Pero sólo para el establecimiento procesal del primero de esos elementos parece tener alguna importancia la "dogmática" o "técnica-jurídica”, según el propio Del Río reconocía. Sin embargo, puesto que hemos "dado por muerto" al positivismo, no tenemos un arsenal conceptual para auxiliar al juez en la labor de establecer el "grado de compromiso delictual”, aparte de la reincidencia, a pesar de que es este aspecto precisamente el determinante a la hora de decidir qué clase de sanción se impondrá en definitiva.

\section{El positivismo en el Anteproyecto de Código Penal de 2005}

En los Principios Orientadores del trabajo del Foro Penal a que hace referencia el Considerando $5^{\circ}$ del Decreto Supremo 334, publicado en el Diario Oficial el 4 de julio de 2003, que le encargó la redacción del Anteproyecto que ahora discutimos, se afirma el derecho penal del acto y la libertad de decisión como fundamento de la responsabilidad penal (Principios 7 y 10); ${ }^{115}$ la necesidad de contar con un régimen de responsabilidad penal diferenciado entre adolescentes y adultos (Principio 5); ${ }^{16}$ la posibilidad de

113 Fuente: Anuario Estadístico Interinstitucional. Santiago: 2005, p. 22 y 28 (las cifras decimales se han aproximado a la unidad).

114 Así, Horvitz L., Mª Inés; López M., Julián. Derecho procesal penal chileno, t. I. Santiago: Editorial Jurídica de Chile, 2002, 437 p., señalan que el "fundamento político-criminal” de la suspensión condicional "consiste en evitar oportunamente los efectos criminógenos del procedimiento penal y la prisión preventiva respecto de imputados por delitos menores y con bajo o inexistente compromiso delictual previo" (p. 353); aunque no le otorgan similar función al “acuerdo reparatorio” (p. 569).

115 “7. No podrá imponerse pena por pensamientos, intenciones, opiniones o estados, características o circunstancias de las personas, sino sólo por conductas perjudiciales, graves y socialmente intolerables ... 10. Tampoco podrá imponerse pena cuando quien ha realizado la conducta delictiva lo ha hecho privado de libertad interna de decisión, por encontrarse en grave riesgo, en extrema necesidad, en situación de error invencible de cualquier naturaleza o en otras circunstancias semejantes".

116 "5. Los delitos cometidos por menores deben ser regulados por un estatuto jurídico diferente del aplicable a los adultos, que, en todo caso, debe considerar al menos las mismas garantías y derechos que 
establecer un sistema vicarial de medidas de seguridad, basado en la determinación de los hechos que las fundamentan con iguales garantías que para la imposición de penas (Principio 6); ${ }^{117}$ y que el sistema de penas permita, pero no imponga more Ludovico, la reinserción social, prohibiéndose las penas de excesiva duración, las cortas y el tratamiento forzado en la ejecución de las penas (Principios 11, 13 y 14). ${ }^{118}$

Todos estos principios se respetan, grosso modo, en el Anteproyecto preparado por la Comisión Foro Penal, según aparece en los Materiales de Discusión respectivos. ${ }^{119}$ Sin embargo, ello no significa que la influencia del positivismo, en la forma descrita en el apartado anterior, no se haya reflejado en su articulado.

En primer lugar, el Anteproyecto sólo se hace cargo de la responsabilidad penal de los adultos (los “ciudadanos” en la nomenclatura funcionalista en boga), dejando para la Ley de Responsabilidad Penal de los Adolescentes la tarea de establecer el sí y el cómo de la reacción social frente a los delitos cometidos por menores de 18 y mayores de 14 años (art. $6^{\circ}, \mathrm{N}^{\circ} 3$ ). Sin embargo, al dejarse expresamente establecido que los mayores de 14 y menores de 18 años sí eran "responsables penalmente", pero sujetos a un régimen jurídico diferente, lo primero que se hace es reconocer la existencia de un vasto ámbito de ejercicio del poder punitivo diferenciado del "derecho penal del ciudadano" ... ipor las características personales del autor, en este caso, su edad! Y según explicamos, ese régimen, como actualmente está concebido, representaría el sueño de un positivismo únicamente moderado por la necesidad de acreditar procesalmente (con las mismas garantías que para los ciudadanos adultos) los hechos calificados de delito y las otras circunstancias que se consideran indicadores del grado de peligrosidad del menor, o en las palabras de la Ley 20.084, de la clase y necesidad del "tratamiento socioeducativo" que mejor conduzca a su "plena integración social".

Por otra parte, mientras se elimina por "peligrosista" la agravante de reincidencia, se mantiene la atenuante de "irreprochable conducta anterior", "por razones de preven-

rigen para éstos. Tanto el catálogo de conductas punibles como las sanciones aplicables deben ser proporcionalmente menos gravosos que los vigentes para los adultos".

117 “6. De establecerse un sistema de medidas de seguridad o corrección, no podrán aplicarse tales medidas sino a quienes sean incapaces de conformar su conducta a la norma, y sólo en cuanto hayan incurrido previamente en un hecho ilícito en condiciones en que a cualquier persona hubiese sido exigible evitarlo. No podrá aplicarse al mismo tiempo y por un mismo hecho una pena y una medida de seguridad o corrección. La aplicación de medidas de seguridad y protección debe estar sujeta a garantías y controles equivalentes a los vigentes para las penas”.

118 “11. Quedan igualmente prohibidas las penas perpetuas y, respecto de las temporales, su duración máxima no debe extenderse a un periodo que importe privar al condenado de la posibilidad efectiva de reinserción social ... 13. La aplicación de penas de encierro debe respetar la dignidad humana. Por consiguiente, sólo pueden propender a la educación o tratamiento del condenado cuando éste libre y voluntariamente consienta en ello. Deberán ser controladas y revisadas periódicamente por parte de una instancia judicial ... 14. Deberá evitarse tanto la amenaza abstracta de penas privativas de libertad de corta duración -procediéndose a la supresión o adecuación de los tipos penales que exclusivamente contemplan ese tipo de penas- como la imposición de penas de estas características en los casos concretos. En estos casos, se deben aplicar penas alternativas que no signifiquen encierro".

119 "Materiales", p. 176 y siguientes. 
ción especial positiva”, pese a la existencia de un importante sector de los miembros del Foro que consideraban "incoherente” esta dicotomía, ante lo cual se argumentó que razones de política criminal harían conveniente "que el primer contacto con el sistema penal sea un contacto atenuado". ${ }^{120}$ Aunque parezca extraño, esta decisión puede verse como una imagen inversa de la discusión legislativa actual sobre el efecto que ha de dársele a la reincidencia, tanto para decretar medidas cautelares personales como en la determinación de la pena: ${ }^{121}$ en ambos casos parece que la "política criminal" está determinada más por intuiciones que por estudios criminológicos que demuestren la efectividad del propósito buscado con tan aparentemente contradictorias medidas: la reducción de la criminalidad (entendida aquí fenomenológicamente como el número de ciertos hechos que suceden en el mundo real y pueden calificarse de delitos según ciertas reglas legales). $\mathrm{Y}$ en ambos casos nos encontramos ante postulados positivistas, pero sin respaldo en la investigación científica que debiera respaldarlos.

En cuanto al sistema de penas, el esfuerzo por racionalizar las disposiciones vigentes, incorporando al texto todas las reglas que efectivamente determinan la pena o medida a imponer, sólo logró dejar todavía más de manifiesto un sistema de corte positivista, donde la decisión final acerca de la clase de reacción social depende de las circunstancias personales del condenado, operando el establecimiento de los hechos constitutivos de delito sólo como "indicadores" de su peligrosidad y, por tanto, de la medida aplicable.

Esto es bien evidente respecto de la "suspensión de la imposición de la condena", regulación tomada del actual art. 398 del Código Procesal Penal, donde atendida la escasa cuantía de la pena a imponer por hechos menos graves (simples delitos), se le permite al juez decidir no imponerla si incurren "antecedentes favorables que no hagan aconsejable su imposición” (art. 54). Naturalmente, esos antecedentes han de estar referidos no al hecho ya juzgado, sino a la persona del autor y a las posibilidades que tenga para su adecuada inserción social sin necesidad de imponerle una pena.

Además, la reincidencia, eliminada del catálogo de circunstancias, pasa a tener en el momento de determinar la reacción social a imponer una relevancia fundamental: sólo quienes no han sido condenados anteriormente por delitos pueden optar a los sustitutos penales de "observación por la autoridad" (nombre con que pasa a denominarse la actual "remisión condicional de la pena") y "libertad vigilada" (arts. $58 \mathrm{~N}^{\circ} 2^{\circ}$ y $59 \mathrm{~N}^{\circ} 2^{\circ}$ ). Las condiciones que se imponen para el cumplimiento de tales sustitutos tienen por objeto la integración social del condenado y, en esa medida, se trata de un sistema claramente positivista. Lo mismo vale para el sistema de libertad condicional (arts. 65 y siguientes).

Finalmente, el Anteproyecto no se hace cargo de las medidas de seguridad para inimputables, dejando su regulación al actual sistema del Código Procesal Penal y del régimen sanitario. Sin embargo, hay en él ciertas "penas" que, si se miran desde el

120 "Materiales", p. 157.

${ }^{121}$ Según aparece claramente en el Mensaje $\mathrm{N}^{\mathrm{o}}$ 188-354, de 7 de julio de 2006, del Proyecto de Ley de la llamada "agenda corta" "en materia de seguridad ciudadana", donde se crea un "estatuto especial para reincidentes en delitos graves”, pues se señala que "una de las principales causas de inseguridad se encuentra en el hecho de que un porcentaje importante de los delincuentes que cometen delitos graves son reincidentes en los mismos hechos". 
punto de vista positivista, sólo están destinadas a cumplir funciones de "prevención especial negativas" o aseguramiento, respecto de ciertos hechos que se estiman tienen su causa en algo que es propio del sujeto al que se le imponen: esto es bien evidente en las sanciones de inhabilitación para conducir vehículos motorizados dispuestas con relación a la comisión de delitos contra la seguridad de los medios de transporte (arts. 215 y siguientes) y en los que intervienen funcionarios públicos (especialmente, arts. 252 y siguientes). Es también una "medida de seguridad" la inhabilitación especial del art. 111 del proyecto, dispuesta para los condenados por delitos de carácter sexual, a fin de impedirles su cercanía a menores de edad. Y en todos estos casos el sistema no es el vicarial, como sucede respecto de los inimputables, sino el de duplo binario, ya que tales reacciones sociales no se consideran "medidas de seguridad", sino "penas", que sí pueden acumularse a otras (¿"fraude de etiquetas al revés?”).

\section{CONCLUSIONES}

El positivismo, al contrario de lo sostenido por nuestra doctrina dominante, no fue un movimiento tardío en Chile ni dejó como secuela sólo una ley inoperante y los fundamentos de las investigaciones criminológicas. Su influencia, bajo diversas denominaciones y justificaciones, permanece vivamente hoy en nuestro sistema legal, en la discusión pública, en la investigación criminológica más avanzada y, por cierto, en el Anteproyecto de Nuevo Código Penal.

Naturalmente, no se trata de un positivismo que haya logrado arrumbar el derecho penal y reemplazarlo por hospitales y otras instituciones similares. Pero no están lejanos a esas ideas los establecimientos especiales que la Ley 20.084 prevé para los infractores adolescentes.

Tampoco ha logrado el positivismo que se deje completamente de lado la dogmática penal, pero indirectamente la ha limitado a una técnica útil para establecer procesalmente si un hecho es de aquellos fenómenos que llamamos delito (y por ello, indicadores de una "peligrosidad" del sujeto, ya concretada) y el máximo temporal de la medida aplicable (la pena determinada legalmente). De allí en adelante, nada tiene que decir la "dogmática" sobre si conviene o no la imposición de una pena, si la "pena" será o no sustituida por una medida alternativa, cuál es la clase de sanción más conveniente para su adecuada inserción social, en los casos de infractores adolescentes, y en qué casos convendrá o no liberar a un condenado antes del término de su pena o suspender su ejecución.

Y tampoco se ha impuesto abiertamente un sistema de medidas de seguridad junto al de penas propiamente tales. Pero ellas ya son parte de nuestra realidad normativa, con nombres diversos en algunos casos, y la discusión, como lo demuestra la polémica acerca de la esterilización solicitada por un condenado en delitos de carácter sexual, está lejos de encontrarse completamente zanjada. ${ }^{122}$

${ }^{122}$ La discusión en España la ha replanteado Silva Sánchez, Jesús Ma " "El retorno de la inocuización: el caso de las reacciones jurídico-penales frente a los delincuentes sexuales violentos en derecho comparado". En 
Por todo lo anterior, podemos afirmar que el positivismo penológico, en nuestro sistema, es un "positivismo contenido", primero, por el límite que representa la determinación procesal de si un hecho que demuestra la peligrosidad del sujeto es o no constitutivo de delito; y en segundo lugar, por la cuantía de la pena determinada judicialmente. Sin embargo, esta última limitación puede referirse únicamente al máximo de la reacción social a imponer, pues bien puede considerarse, como parece suceder en la realidad actual por el juego de circunstancias (especialmente la reincidencia), que imponer una pena privativa de libertad superior a cinco años es un claro indicador de lo "peligroso" que se considera al agente y, en esa medida, cumple principalmente una función de custodia de seguridad.

En uno de sus numerosos escritos sobre la idea del "derecho penal del enemigo", Jakobs nos invita a soportar la mirada aunque el espejo nos devuelva una imagen desagradable de la que uno esperaría de sí mismo. En ese mismo lugar se define como "derecho penal del enemigo" aquel que trata al individuo no como persona (significativamente), sino como individuo peligroso, respecto del cual la reacción social es pura coacción para su custodia. Se supone, en los textos de Jakobs, que las "manifestaciones" de este derecho penal del enemigo serían aisladas, una suerte de "mancha" dentro del derecho penal del ciudadano. Sin embargo, es probable que la realidad sea la inversa, esto es, que todo nuestro derecho penal (en los hechos) por hacer gravitar reacción social en la mayor o menor peligrosidad del condenado, sea completamente "derecho penal del enemigo" "en sentido amplio: incluyendo el Derecho de las medidas de seguridad", 123 que está solamente "contenido" o "limitado", por no renunciar (todavía) el Estado a mantener ciertos derechos: el proceso legal para determinar la responsabilidad penal y la limitación temporal de la reacción social a la previsión legal previa.

Todavía podemos ir más allá en la incomodidad: ¿serán estas limitaciones que impone el derecho penal al tratamiento de los infractores a la ley lo que produce la sensación de insatisfacción de la comunidad política respecto del sistema penal?, como quisiéramos todos creer; ¿provendrá esa insatisfacción del reemplazo en cierta práctica judicial de la investigación del carácter peligroso de los imputados y de la imposición de las medidas adecuadas a su peligrosidad, por la intuición personal de los magistrados?; o prevendrá del hecho de que las contenciones del derecho penal hacen que el sistema siga sin poder dar respuesta a los reclamos que dieron lugar a la Escuela Positiva: ineficacia en la reducción del delito e inequidad social en su persecución.

\footnotetext{
Redondo I., Santiago (ed.). Delincuencia sexual y sociedad. Barcelona: Ariel, 2002, p. 143-160. En Alemania, ha sido un ícono del "buen y viejo derecho penal liberal" quien ha puesto de nuevo sobre la mesa la necesidad de construir un "derecho penal de la seguridad": Hassemer, Winfried. "Strafrecht, Prävention, Vergeltung”. Zeitschrift für die internationale Strafrechtsdogmatik. 7/2006, p. 266-273.

123 Jakobs, Günther. "Derecho penal del ciudadano y Derecho penal del enemigo”. En Jakobs / Cancio M., Manuel. Derecho penal del enemigo. Buenos Aires: Hammurabi, 2005, p. 19-64, p. 31. Una última versión del concepto en el propio Jakobs puede verse en su "Terroristen als Personen im Recht?". Zeitschrift für die Gesamte Strafrechtswissenschaft, t. 117, 2005, p. 839-852.
} 


\section{BIBLIOGRAFÍA}

Abarza Y., René. Pedro Pablo Ortiz Muñoz. Vida, obra e influencia en el Derecho penal chileno, tesis UTALCA. Dir.: J.P. Matus. Talca, 2005, 55 p.

Acevedo H., Amador. Del abuso de firma en blanco. Tesis UCH. Santiago: El Imparcial, 76 p. Agüero C., Guillermo. "Aspectos de nuestra delincuencia femenina”. Revista de Ciencias Penales, t. IV, 1938, p. 61-78.

- “Análisis de la 'pequeña delincuencia' en Chile”. Revista de Ciencias Penales, t. V, 1941, p. 61-78.

Aguirre G., Manuel. De los delitos contra la seguridad interior del Estado. Tesis UCH. Santiago: La Nación, 1932, 134 p., entre otras.

Aguirre, Santiago. De las lesiones. Tesis UCH. Santiago: Comercial, 1922, 56 p.

Alcayaga V., Marta. La responsabilidad penal del médico. Tesis UCH. Valparaíso: Royal, 1939, $69 \mathrm{p}$.

Alessandri R., Arturo; Benavente, D. "El recurso de casación en materia penal en la legislación chilena”. Revista de Ciencias Penales, t. IV, 1938, p. 36-60.

Alessandri R., Fernando. "La condena por perjuicios en el proceso penal". Revista de Ciencias Penales, t. V, 1941, p. 103-110.

Almarza P., Olga. El delito de encubrimiento. Tesis UCH. Santiago: Rapid, 1941, 53 p.

Alsina A., Javier. El delito de prevaricación. Tesis UCH. Chillán: Alsina, 109 p.

Antony García, Carmen. Las mujeres confinadas. Estudio criminológico sobre el rol genérico en la ejecución de la pena en Chile y América Latina. Santiago; 2000.

Araya Moya, Jorge; Sierra Cisternas, David. Influencia de factores de riesgo social en el origen de conductas delictuales. Índice de vulnerabilidad social, delincuencia comunal. Santiago: División de Seguridad Ciudadana del Ministerio del Interior, 2002.

Baeza, Mario. Esquema y notas para una historia de la Facultad de Ciencias Jurídicas y Sociales de la Universidad de Chile. Santiago: Memoria de Prueba (Universidad de Chile), 1944. 237 p., p. 182 y siguiente.

Ballivián H., José. El delito de apropiación indebida (art. $470 \mathrm{~N}^{\circ} 1$ del Código penal). Tesis UCH. Santiago: La Gratitud, 1937, 67 p.

Belmar, Roberto; Gandulfo, Pedro; Guerrero, Juan. Derecho penal. Apuntes tomados en clase de don Ricardo Cabieses, ampliados y redactados. Santiago: Imp. Estrella del Pacífico, $1918,223 \mathrm{p}$.

Brandeau G., Valentín. De la Represión y Prevención del Delito en Chile. Santiago: La Ilustración, 1917,293 p.

- Política Criminal Represiva. Santiago: Imprenta Cervantes, 1909, 201 p.

- "Introduccción al Estudio del Derecho penal”. Revista de Ciencias Penales, t. I, 1935, p. $122-$ 137 y $302-317$.

Bravo, Alfredo G. "El estado peligroso". Revista de Ciencias Penales, t. I, 1935, p. 5-12.

BrüCher E., EdUARDo. "El nuevo método de defensa social: la esterilización”. Revista de Ciencias Penales, t. I, 1935, p. 34-40.

- "Consideraciones sobre la reincidencia delictual en Chile". Revista de Ciencias Penales, t. IV, 1938, p. 57-60.

- "Anotaciones médico-legales al Proyecto de Código Penal Silva-Labatut". Revista de Ciencias Penales, t. IV, 1938, p. 471-479.

Brzovic R., Miguel. Los Institutos y Seminarios de Criminología y Bases generales para el nuevo Código Penal. Tesis UCH. Santiago: Imp. Austral, 1928, 127 p. En la misma línea de reforma penal, encontramos antes la memoria de Rojo C., Enrique. Tres instituciones penales prácticas y modernas. Tesis UCH. Santiago: La Economía, 1923, 79 p. 
Cabello De La Fuente, Carlos. Rafael Fontecilla Riquelme. Vida, obra e influencia en el Derecho penal chileno. Tesis UTALCA. Dir.: J.P. Matus. Talca, 2005, 60 p.

Cabrera B., Gonzalo. Del concepto jurídico de delito. Tesis UCH. Santiago: Leblanc, 1941, $78 \mathrm{p}$.

Cea, Macarena; Ruiz, Paulina; Matus, Jean Pierre. "Determinantes de la criminalidad. Revisión bibliográfica”. Polít. crim. $\mathrm{N}^{\circ} 2,2006, \mathrm{D} 4$.

Cea, Macarena; Ruiz, Paulina; y Matus, Jean Pierre. "Determinantes de la criminalidad: revisión bibliográfica". Polít. crim. $\mathrm{N}^{\circ}$ 2. D4, p. 1-34.

Cooper A., Federico. El concurso de delincuentes. Tesis UCH. Santiago: Artes y Letras, 1929, $82 \mathrm{p}$.

Correa O., Samuel. De las penas y los sistemas penitenciarios. Tesis UCH. Santiago: Cervantes, 1902, 33 p.

Cousiño, Luis. Derecho penal chileno, t. I. Santiago: Editorial Jurídica de Chile, 1975. 960 p., p. 68 .

Cubillos, Luis. "Delincuencia: Problema biológico-social y legal". Revista de Ciencias Penales, t. I, 1935, p. 146-153, 324-332 y p. 488-498.

- $\quad$ "La realidad médico-social de nuestra población carcelaria". Revista de Ciencias Penales, t. VI, 1942, p. 391-395.

Cuevas C., Luis. La pericia Médico-Legal. Sus imperfecciones en la práctica. Tesis UCH. Santiago: La Economía, 1921, 43 p.

Cury U., Enrique. Derecho penal. Parte General. $7^{\mathrm{a}}$ ed. Santiago: Ediciones Universidad Católica de Chile, 2005.812 p., p. 161.

De Ramón, Armando y otros. Biografías de Chilenos. Vol. III. Santiago: Ediciones de la P. U. Católica de Chile, 2003, 298 p., p. 46, Nº 2083.

Del Río, Raimundo. Derecho penal. Notas tomadas en clase del profesor Señor don Ricardo Cabieses. Santiago: Imp. Universitaria, 1915, $51 \mathrm{p}$.

- El problema penal. TU. Santiago, Imp. Univ., 1916, 104 p.

- "Clase Inaugural del Curso de Derecho Penal de la Universidad de Chile". Revista de Derecho, t. XVII, Nos. 1-2, marzo-abril de 1920. p. 18-26.

- Derecho penal, t. I. Santiago: Nascimento, 1935. 320 p.

- Explicaciones de Derecho penal, t. II. Santiago: Nascimento, 1945. 366 p.

Donoso H., Óscar. La tentativa y el delito frustrado. Tesis UCH. Santiago: Inglesa, 1923, $119 \mathrm{p}$.

Drapkin, Abraham. Jurisprudencia de las circunstancias eximentes de responsabilidad criminal. Tesis UCH. Santiago, 1936, 113 p.

- "Jurisprudencia de la eximente por enajenación mental". Revista de Ciencias Penales, t. II, 1936, p. 518-537.

- "La menor edad". Revista de Ciencias Penales, t. III, 1937, p. 53-59.

- "Defensa legítima". Revista de Ciencias Penales, t. IV, 1938, p. 36-56.

- "Uxoricidio por adulterio". Revista de Ciencias Penales, t. IV, 1938, p. 406-415.

- "Apuntes para la formación del vocabulario del hampa chilena". Revista de Ciencias Penales, t. IV, 1938, p. 484-492.

- Relación de causalidad y delito. Santiago: Cruz del Sur, 1943, 114 p.

Drapkin, Israel. Criminología y Ciencia Penitenciaria. Santiago: Imp. de Prisiones, 1941, 20 p.

- $\quad$ "La libertad condicional en Chile. Revista de Ciencias Penales, t. VIII, 1945, p. 103.

- "Algunas consideraciones acerca de la criminalidad entre los araucanos". Revista de Ciencias Penales, t. X, No 2-3, 1948, p. 106.

- Prensa y Criminalidad. Santiago: Anales U. de Chile, 1958, 131 p. 
Drapkin, Israel; Agüero, Guillermo; Cubillos, Luis. "Proyecto de Ficha Criminológica del Instituto de Clasificación y Criminología de la Penitenciaría de Santiago". Revista de Ciencias Penales, t. II, 1936, p. 381-427.

Drapkin, Israel; BrüCher E., Eduardo. Criminología y Ciencia penitenciaria. Santiago: Imp. Prisiones, 1941, 20 p.

Dubber D., Markus. "Positive Generalprävention und Rechtsgutstheorie: Zwei zentrale Errungenschaften der deutschen Strafrechtswissenschaft aus amerikanischer Sicht". Zeitschrift für die gesamte Strafrechtswissenchaft, t. 117, 2005, p. 485-518, p. 415.

Escudero O., JaCinto. Los menores ante la legislación penal. Tesis UCH. Santiago: La Tribuna Ilustrada, 1917, $54 \mathrm{p}$.

Espejo E., Humberto. Estudio Jurídico y Médico Legal del Ebrio. Problema social del alcoholismo. Tesis UCH. Santiago. El Globo, 1926, 83 p.

Espinoza H., Mauricio; Labatut Glena Gustavo. Vida, obra y aporte al Derecho penal actual. Tesis UTALCA. Dir.: J.P. Matus A. Talca, 2005, 65 p.

Espinoza S., Claudio. El delito de lesiones. Tesis UCH. Santiago: Manila, 146 p.

Etcheberry O., Alfredo. Derecho penal, t. I. $3^{a}$ ed. Santiago: Editorial Jurídica de Chile, 1998. 361 p., p. 59.

Ferri, Enrico. La sociologie criminelle. Paris: Félix Alcan, 1914.

Ferri, Enrique. Principios de Derecho Criminal. Delincuente y delito en la ciencia, la legislación y la jurisprudencia. Trad. J. Rodríguez Muñoz. Madrid: Reus, 1933, 820 p.

Fontecilla A., Juan. "La apelación del sobreseimiento definitivo en el Código de Justicia Militar". Revista de Ciencias Penales, t. V, 1941, p. 333-340.

Fontecilla R., Rafael. La pena. Santiago: Cisneros, 1931, 420 p.

- "El concepto jurídico de delito y sus principales problemas técnicos". Revista de Ciencias Penales, t. II, 1936, p. 21-51.

- "Geheimrat". Anales de la Universidad de Chile. Primer trimestre, 1933, p. 41-52.

- "El juicio penal". Revista de Ciencias Penales, t. V, 1941, p. 7-23.

- Concursos de delincuentes, de delitos y de leyes penales y sus principales problemas jurídicos. Santiago: Editorial Jurídica de Chile, 1956, 121 p.

Gajardo, Samuel. Medicina Legal. Santiago: Nascimento, 1931 (1 ${ }^{\mathrm{a}}$ ed., 353 p.) y 1939 (2a ed., 2 t., 413 y 428 p.).

- Justicia con alma. Santiago: Imp. Prisiones, 1926.

- Los derechos del niño y la tiranía del ambiente. Santiago: 1929, 179 p.

- Delincuencia infantil. Santiago: Imp. Prisiones, 1940, 294 p.

- Memorias de un Juez. Santiago: 1957, 222 p.

- Protección de menores. Santiago: Ed. Jurídica de Chile, 1955, 124 p.

- "Conceptos modernos de Derecho penal". Revista de Derecho y Jurisprudencia, t. III, 1934, p. 33-36.

- Ensayo sobre el hombre antisocial. Santiago: Cervantes, 1942, 130 p.

- La vida sexual ante el Derecho. Santiago: Cervantes, 1944, 158 p.

- Reflexiones sobre la pena de muerte. Santiago: Universo, 1946, 88 p.

Gallardo Nieto, Galvarino. Defensa del Canódromo de Beneficencia ante la Excma. Corte Suprema. Santiago: La Ilustración, 1935, 224 p.

Gambara, Luis. Curso de Derecho penal positivo. Santiago: Hnos. Ponce, 1906. 184 p.

Gamboa S., Carmen. Cuestiones de Antropología Jurídica. Tesis UCH. Valparaíso: Imp. La Armada, 1924, 63 p. Un aspecto específico de esta temática es tratado después por Scheggia F., Mario. La reincidencia y su comprobación. Tesis UCH. Santiago: El Cóndor, 1929, 64 p.

García G., Eduardo. Estudio sobre Antropología Criminal. Tesis UCH. Santiago, 1911, 26 p. 
Garófalo, Raffaele. La criminología: estudio sobre el delito y sobre la teoría de la represión. Trad. P. Dorado Montero. Madrid: La España Moderna, 1885.

Garrido Montt, Mario. Derecho penal. Parte general. Nociones fundamentales de la Teoría del Delito, t. II. $3^{\mathrm{a}}$ ed. Santiago: Editorial Jurídica de Chile, 2003. 358 p.

Gesche, Bernardo. La remisión condicional de la pena. Santiago: Editorial Jurídica de Chile, $1975,314 \mathrm{p}$.

Gimbernat O., EnRiQue. “¿Tiene un futuro la dogmática juridicopenal”. En Problemas actuales del Derecho penal y procesal. Salamanca, 1971, p. 87-109.

GonzÁlez Berendique, Marco A. Criminología. 2 vols. Santiago: Editorial Jurídica de Chile, 1998

GoyeneChe P., Raúl. ¿Pueden querellarse las personas jurídicas? Tesis UCH. Santiago: La Compañía, 1929, 89 p.

Hassemer, Winfried. "Strafrecht, Prävention, Vergeltung". Zeitschrift für die internationale Strafrechtsdogmatik. 7/2006, p. 266-273.

Hofer D., M $M^{a}$ Eugenia. "20 años de aplicación de la Ley No 18.216". Boletín Jurídico del Ministerio de Justicia. $\mathrm{N}^{\text {os. }}$ 4-5, 2003, p. 157-185.

Horvitz L., Ma Inés; López M., Julián. Derecho procesal penal chileno, t. I. Santiago: Editorial Jurídica de Chile, 2002, 437 p.

Jakobs, Günther. Strafrecht. Allgemeiner Teil. 2a ed. Berlin: De Gruyter, 1991, 944 p.

- "Derecho penal del ciudadano y Derecho penal del enemigo". En Jakobs / Cancio M., Manuel. Derecho penal del enemigo. Buenos Aires: Hammurabi, 2005, p. 19-64, p. 31.

- “Terroristen als Personen im Recht?”. Zeitschrift für die Gesamte Strafrechtswissenschaft, t. 117, 2005, p. 839-852.

Jaque A., Paulina. José Raimundo del Río. Vida, obra e influencias en el Derecho penal. Tesis UTALCA. Dir.: J.P. Matus. Universidad de Talca, 2005, 71 p., p. 5-13.

Jiménez De Asúa, Luis. Tratado de Derecho penal, t. I. $5^{a}$ ed. Buenos Aires: Losada, 1950, $1435 \mathrm{p}$.

- Tratado de Derecho penal, t. II. $5^{a}$ ed. Buenos Aires: Losada, 1950, 1439 p.

JimÉneZ, Ma AngéLICA. "Núcleos problemáticos de las medidas alternativas a la privación de libertad (Referencia a países de América Latina)". Cuadernos de Análisis Jurídico $\mathrm{N}^{\circ} 30$, 1994 , pp. 41-52.

Labatut Glena, Gustavo. "La peligrosidad de las personas naturales en el Proyecto de Código Penal Chileno". Revista de Ciencias Penales, t. IV, 1938, p. 289-296.

- Manual de Derecho penal. Santiago: s/e, 1948, 551 p.

- Manual de Derecho penal, t. I. $3^{a}$ ed. Santiago: Ed. Jurídica de Chile, 1958, 480 p.

Lazo, Santiago. El Crimen de Lo Vicuña. Santiago: Universo, 1921, 141 p.

Letelier, Valentín. Jénesis del Derecho. Santiago y Buenos Aires: Hume \& Walker y Cabaut \& Cía, 1919. 727 p., p. 414.

Lira V., Rigoberto. La Escuela Criminal positiva. Tesis UCH. Santiago, 1917, 16 p.

Lombroso, César. L'Homme Criminel. Atlas. 12a ed. Turin: Bocca Frères, 1888, 90 "planchas". Manríquez C., Carlos. Concurso o acumulación de delitos. Tesis UCH. Santiago, 1935, 143 p.

Marín, Urbano. "La libertad condicional en Chile". Revista de Ciencias Penales, t. V, 1941, p. 206-240.

Matus A., Jean Pierre. "Fernández, Fuenzalida y Vera: Comentaristas, autodidactas y olvidados. Análisis diacrónico y sincrónico de la doctrina penal chilena del siglo XIX". Ius et Praxis. Año 12, $\mathrm{N}^{\circ}$ 1, 2006, p. 31-67.

Ministerio de Justicia y Otros. Anuario Estadístico Interinstitucional. Santiago: 2005, 272 p.

Montero Schmidt, Mario. "El pensamiento jurídico penal de Pedro Ortiz". Revista de Ciencias Penales, t. X, No 2, 1948, p. 110 y siguiente. 
Novoa M., Eduardo. Curso de Derecho penal, t. I. Santiago: Editorial Jurídica de Chile, 1960. 618 p., p. 90.

Ochagavía H., Ignacio. La legislación, ante el problema del Alcobolismo. Tesis UCH. Santiago: Cervantes, 1917, $60 \mathrm{p}$.

Orrego V., Germán. Delitos de imprenta o de publicación. Tesis UCH. Santiago, 1937, 182 p.

Ortiz Muñoz, Pedro. Nociones Generales de Derecho Penal, t. I. Santiago: Nascimento, 1933, $226 \mathrm{p}$.

- "Los Problemas de la Reforma Penal”. Revista de Ciencias Penales, t. I, 1935, p. 13-15.

- Nociones de Derecho Penal, t. II. Santiago: Nascimento, 1937, 214 p.

- Curso Breve de Derecho penal, común y militar. Santiago: Imp. Carabineros de Chile, 1947.

- "Voluntariedad y otras cuestiones". Revista de Ciencias Penales, t. V, 1941, p. 372-388.

Peña, Federico. "Del robo con homicidio". Revista de Ciencias Penales, t. I, 1935, p. 21-28.

- "La confesión como medio de prueba". Revista de Ciencias Penales, t. I, 1935, p. 296-301.

- $\quad$ "Observaciones al nuevo Proyecto de Código Penal”. Revista de Ciencias Penales, t. IV, 1938, p. 379-393 y $465-470$.

- "El poder de policía y la prevención del delito". Revista de Ciencias Penales, t. II, 1936, p. 108-113, 229-239 y 553-561; y Revista de Ciencias Penales, t. III, 1937, p. 342-359.

Politoff, Sergio. Derecho penal. $2^{a}$ ed. Santiago: Editorial Jurídica Cono Sur, 2001. 497 p., p. 50.

Politoff, Sergio; Matus, Jean Pierre; Ramírez, Ma Cecilia. Lecciones de Derecho penal. Parte general. $2^{a}$ ed. Santiago: Editorial Jurídica de Chile, 2004. 613 p., p. 33.

Rencoret D., Raúl. De la confesión judicial y especialmente de su divisibilidad e indivisibilidad. Tesis UCH. Santiago: La Ilustración, 1925, 54 p.

Rivacoba y Rivacoba, Manuel. Evolución histórica del Derecho penal Chileno. Valparaíso: EDEVAL, 1991, 151 p., p. 86-96 y 109-112.

Schweitzer S., Miguel. "El delito de acusación o denuncia calumniosa". Revista de Ciencias Penales, t. III, 1937 , p. 342-359.

- "Marginando una sentencia". Revista de Ciencias Penales, t. I, 1935, p. 197-199.

- "Síntesis de la legislación chilena de menores". Revista de Ciencias Penales, t. IV, 1938, p. 310-316.

Secretaría Técnica de la Comisión Foro Penal. "Materiales de Discusión presentados a la Comisión Foro Penal, Parte General". Polít. crim, No 1, D2, p. 1-223.

SILVA SÁNCHEZ, Jesús Ma. "El retorno de la inocuización: el caso de las reacciones jurídico-penales frente a los delincuentes sexuales violentos en derecho comparado". En Redondo I., Santiago (ed.). Delincuencia sexual y sociedad. Barcelona: Ariel, 2002, p. 143-160.

- "Del Derecho abstracto al Derecho "real”. Recensión a Günther Jakobs, La pena estatal: significado y finalidad (traducción y estudio preliminar de M. Cancio Meliá y B. Feijóo Sánchez), Thomson-Civitas, Madrid, 2006, 182 pág.”. In Dret. 4/2006, No 377, p. 1-6.

Szerer, Mieczyslaw. Conception sociologique de la Peine. Paris, 1914, 205 p.

Valdovinos, Carlos. "El delito de incendio con fines de lucro". Revista de Ciencias Penales. t. IV, 1938, p. 12-35.

Valenzuela G., Manuel. El delito y su represión. Tesis UCH. Santiago: Imp. Encina, 1907, $26 \mathrm{p}$.

Varas V., Eduardo. "Comunicabilidad a los co-delincuentes de los elementos constitutivos de un delito". Revista de Ciencias Penales, t. V, 1941, p. 49-56.

Verdugo L., Alberto. Estudios de Medicina Legal. Santiago: Imp. Universitaria, 1920, 74 p.

VICUÑa S., Luis. "Observación al régimen procesal de los menores”. Revista de Ciencias Penales, t. III, 1937, p. 198-232.

Vieytes P., Irlanda. El problema de la Esterilización de Anormales y Delincuentes. Tesis UCH. Santiago: Talleres "El Chileno", 1947, 50 p. 
